\title{
An Investigation of the Adsorption of Xanthate on Bornite in Aqueous Solutions Using an Atomic Force Microscope
}

\author{
Jinhong Zhang
}

Citation: Zhang, J. An Investigation of the Adsorption of Xanthate on

Bornite in Aqueous Solutions Using an Atomic Force Microscope. Minerals 2021, 11, 906. https:// doi.org/10.3390/min11080906

Academic Editors: Shuai Wang,

Xingjie Wang, Jia Yang

and Lev Filippov

Received: 22 July 2021

Accepted: 18 August 2021

Published: 21 August 2021

Publisher's Note: MDPI stays neutral with regard to jurisdictional claims in published maps and institutional affiliations.

Copyright: (C) 2021 by the author. Licensee MDPI, Basel, Switzerland. This article is an open access article distributed under the terms and conditions of the Creative Commons Attribution (CC BY) license (https:// creativecommons.org/licenses/by/ $4.0 /)$.
Department of Mining and Geological Engineering, The University of Arizona, Tucson, AZ 85721, USA; jhzhang@email.arizona.edu

\begin{abstract}
An atomic force microscope (AFM) was applied to study of the adsorption of xanthate on bornite surfaces in situ in aqueous solutions. AFM images showed that xanthate, i.e., potassium ethyl xanthate (KEX) and potassium amyl xanthate (PAX), adsorbed strongly on bornite, and the adsorbate bound strongly with the mineral surface without being removed by flushing with ethanol alcohol. The AFM images also showed that the adsorption increased with the increased collector concentration and contact time. Xanthate adsorbed on bornite in a similar manner when the solution $\mathrm{pH}$ changed to $\mathrm{pH}$ 10. The AFM force measurement results showed that the probe-substrate adhesion increased due to the adsorption of xanthate on bornite. The sharp "jump-in" and "jump-off" points on force curve suggest that the adsorbate is not "soft" in nature, ruling out the existence of dixanthogen, an oily substance. Finally, the ATR-FTIR (attenuated total reflection-Fourier-transform infrared) result confirms that the adsorbate on bornite in xanthate solutions is mainly in the form of insoluble cuprous xanthate $(\mathrm{CuX})$ instead of dixanthogen. This xanthate/bornite adsorption mechanism is very similar to what is obtained with the xanthate/chalcocite system, while it is different from the xanthate/chalcopyrite system, for which oily dixanthogen is the main adsorption product on the chalcopyrite surface. The present study helps clarify the flotation mechanism of bornite in industry practice using xanthate as a collector.
\end{abstract}

Keywords: flotation; xanthate; adsorption; bornite; cuprous xanthate; AFM; FTIR

\section{Introduction}

Flotation has been widely studied as the most efficient separation technique in the copper extraction industry. The adsorption of the collector on the mineral surface is vital for a successful flotation process to achieve a recovery. Historically, many works have been carried out to clarify the adsorption mechanism of collectors on sulfides [1-6].

Compared to other copper minerals, such as chalcopyrite and chalcocite, the adsorption of collector on bornite has been rarely studied. Allison et al. [3] studied the reaction products of various sulfide minerals with xanthate solutions. The authors reported that the measured rest potential of bornite in $6.25 \times 10^{-4} \mathrm{M} \mathrm{KEX}$ solution at $\mathrm{pH} 7$ was $+60 \mathrm{mV}$, and the reaction product of PAX on bornite was cuprous alkyl xanthate. Mielczarski and Suoninen [7,8] applied XPS and studied the adsorption of potassium ethyl xanthate on cuprous sulfide. The authors reported that there was a relatively rapid formation of a well-oriented monolayer of xanthate ions followed by a slow growth of disordered cuprous xanthate molecules on top of this layer. Buckley et al. [9] investigated the surface oxidation of bornite by linear potential sweep voltammetry and X-ray Photoelectron Spectroscopy, and proposed the adsorption products on bornite depended on the solution potential. Zachwieja et al. [10] studied the electrochemical flotation of the bornite-ethylxanthate system and reported that KEX reacted with bornite through an electrochemical oxidation reaction, forming cuprous xanthate between $-0.4 \mathrm{v}$ and $-0.2 \mathrm{v}$ (SCE, saturated calomel electrode). Hangone et al. [11] studied the flotation of a bornite-rich copper sulfide ore using thio collectors and their mixtures, and reported that the highest copper recoveries 
were obtained with the diethyl dithiophosphate (di $\mathrm{C}_{2}$-DTP). Recently, Dhar et al. [12] investigated the improvement of the copper recovery from Nussir Copper Ore Deposit in Northern Norway, using the blend of xanthate and dithiophosphate as collectors.

These previous studies have revealed a significant amount of information, such as the possible reaction product and reaction mechanism of the adsorption of collectors on the bornite surface. Technically, it is also of great interest to directly obtain the image of the collector on the bornite surface changing with the pulp chemistry, such as the type and dosage of chemicals, solution $\mathrm{pH}$ and adsorption time. An autoradiography technique was first applied by Polkin et al. [13] and Plaksin et al. [14] to obtain the images of xanthate radioactive isotopes absorbed on sulfide minerals. The authors reported that there was a mosaic distribution of xanthate collectors on the sulfide mineral surface. Later, scanning tunneling microscopy (STM) was applied by Kim et al. [15] and Smart et al. [16] to collect surface images for the study of the reaction, i.e., oxidation, reaction and absorption, of the galena surface under flotation-related conditions. The reported STM images showed that the pulp chemistry, such as the $\mathrm{pH}$ and chemical dosage, impacted the reaction and its products on the galena surface. Recently, the AFM imaging technique has also been successfully applied for the in situ study of the adsorption of chemicals on various mineral surfaces [17-22]. The novel analysis method has greatly expanded the understanding of the impact of solution chemistry on the collectors' adsorption on mineral surface and the flotation mechanism.

In the present investigation, an AFM was applied to obtain the surface morphology of bornite in KEX and PAX solutions. By comparing the AFM images obtained under different conditions, such as the collector's type, dosage and contacting time, we studied the impact of water chemistry on the adsorption of collectors on bornite. The results will help answer important questions, such as (1) What is the morphology of the adsorbate on mineral surface? (2) What is the impact of the collector's dosage, the contacting time and the solution $\mathrm{pH}$ on the adsorption of the collector on the mineral surface? This information will help to clarify the reaction and adsorption mechanisms of xanthate on bornite changing with aqueous solutions, and therefore its impact on bornite flotation.

\section{Materials and Methods}

\subsection{Materials}

Research-grade bornite $\left(\mathrm{Cu}_{5} \mathrm{FeS}_{4}\right)$ and chalcopyrite $\left(\mathrm{CuFeS}_{2}\right)$ were obtained from Wards Natural Science Establishment Inc. Mineral samples were finely polished by consecutively using \#800, \#1200 and \#2400 sandpaper, and then diamond-polishing paste of 10, 5, 2.5 and 1 microns. (MTI Inc., Richmond, CA, USA) Mineral samples were further cleaned by rinsing thoroughly with ethanol and water. A $1.2 \mathrm{~cm} \times 1.2 \mathrm{~cm}$ sample was used for the surface characterization, i.e., AFM and ATR-FTIR analysis. The DI (deionized) water used in the present work had a conductivity of $18.2 \mathrm{M} \Omega \cdot \mathrm{cm}^{-1}$ at $22{ }^{\circ} \mathrm{C}$ and a surface tension of $72.8 \mathrm{mN} / \mathrm{m}$ at $22{ }^{\circ} \mathrm{C}$. Potassium amyl xanthate (PAX, $\left.>98 \%\right)$, potassium ethyl xanthate (KEX, $>98 \%$ ) and $\mathrm{NaOH}(>99 \%)$ were obtained from Alfa Aesar and used without further purification. Xanthate solutions were freshly prepared at various concentrations and $\mathrm{pH}$ levels as needed each time right before an experiment was carried out.

\subsection{AFM Surface Image and Force Measurements}

AFM surface image measurements were carried out with a Digital Instrument Nanoscope IIID (Veeco, San Jose, CA, USA) AFM using the contact mode at room temperature $\left(22 \pm 1^{\circ} \mathrm{C}\right)$. SNL cantilevers were obtained from Veeco (San Jose, CA, USA). Triangular $\mathrm{Si}_{3} \mathrm{~N}_{4}$ cantilevers with a nominal spring constant of $0.12 \sim 0.58 \mathrm{~N} / \mathrm{m}$ were used for both AFM imaging and force measurements. For the force measurements, the separation distance $(\mathrm{H})$ between the probe and the substrate (bornite plate) was measured by monitoring the deflection of the cantilever.

To study the mineral surface in water, surface image measurements were carried out after $5 \mathrm{~mL}$ DI water was gently injected into an AFM fluid cell. Extreme care was taken to avoid the entrapment of air in the cell. After force data and surface images were collected 
in water, a $10 \mathrm{~mL}$ solution of a specific chemical's concentration was flushed through the liquid cell, and the cell was left undisturbed for the adsorption of chemicals on mineral surface. AFM image analysis and force measurement were commenced after the exposure of the mineral plate to the chemical's solution for a specific time. The AFM images as reported in this study, which were processed by no image modification other than being flattened, include both height and deflection images obtained in the contact mode. The same silicon nitride probe used for the force measurement was also applied to obtain the AFM image of the mineral plate in the solutions at different conditions.

\subsection{ATR-FTIR Measurement}

A Nicolet 6700 Fourier-transform infrared spectrometer (Thermo Electron North America LLC, West Palm Beach, FL, USA) equipped with the Smart iTR accessory was used to collect the mid-infrared spectra. The system was equipped with a liquid-nitrogen-cooled DTGS KBr detector and a diamond ATR crystal with an angle of incidence of $45^{\circ}$ to ensure the signals were detected. First, the mineral was put on the stage with the freshly polished surface, which was pressed and fastened toward the ATR crystal to collect the background spectra. Second, the same sample was removed from the stage, and a $5 \mathrm{~mL}$ xanthate solution of different concentrations was carefully dipped onto the fresh surface and left untouched for a specific time. Third, the mineral sample was tilted to remove most of the solution and gently blown with ultrapure $\mathrm{N}_{2}$ gas for the removal of residual water. Finally, the mineral sample was again pressed against the ATR crystal, and the ATR-FTIR spectra were collected. The intensities in the spectra were shown in a relative value under the same scale. All spectra were collected at room temperature with no further treatment made toward the spectra except the baseline correction.

\section{Results}

\subsection{AFM Image of Minerlal Surface in Various Xanthate Solutions}

Figure 1 shows the surface images of a bare bornite surface obtained in air. Figure $1 \mathrm{~A}$ is the $5 \mu \mathrm{m} \times 5 \mu \mathrm{m}$ height image with a data scale of $20 \mathrm{~nm}$, which shows that the solid surface was quite smooth despite some scratch lines on the sample surface due to surface polishing. A smooth bare mineral surface is beneficial for the identification and analysis of the adsorbate when the surface contacts the solutions of various collectors. Figure 1B is the 3D image of Figure $1 \mathrm{~A}$. Figure $1 \mathrm{C}$ is the section analysis of Figure $1 \mathrm{~A}$, which confirms that the polished bornite surface was quite smooth. Figure 1D is the deflection image of Figure 1A with a $10 \mathrm{~nm}$ data scale. 

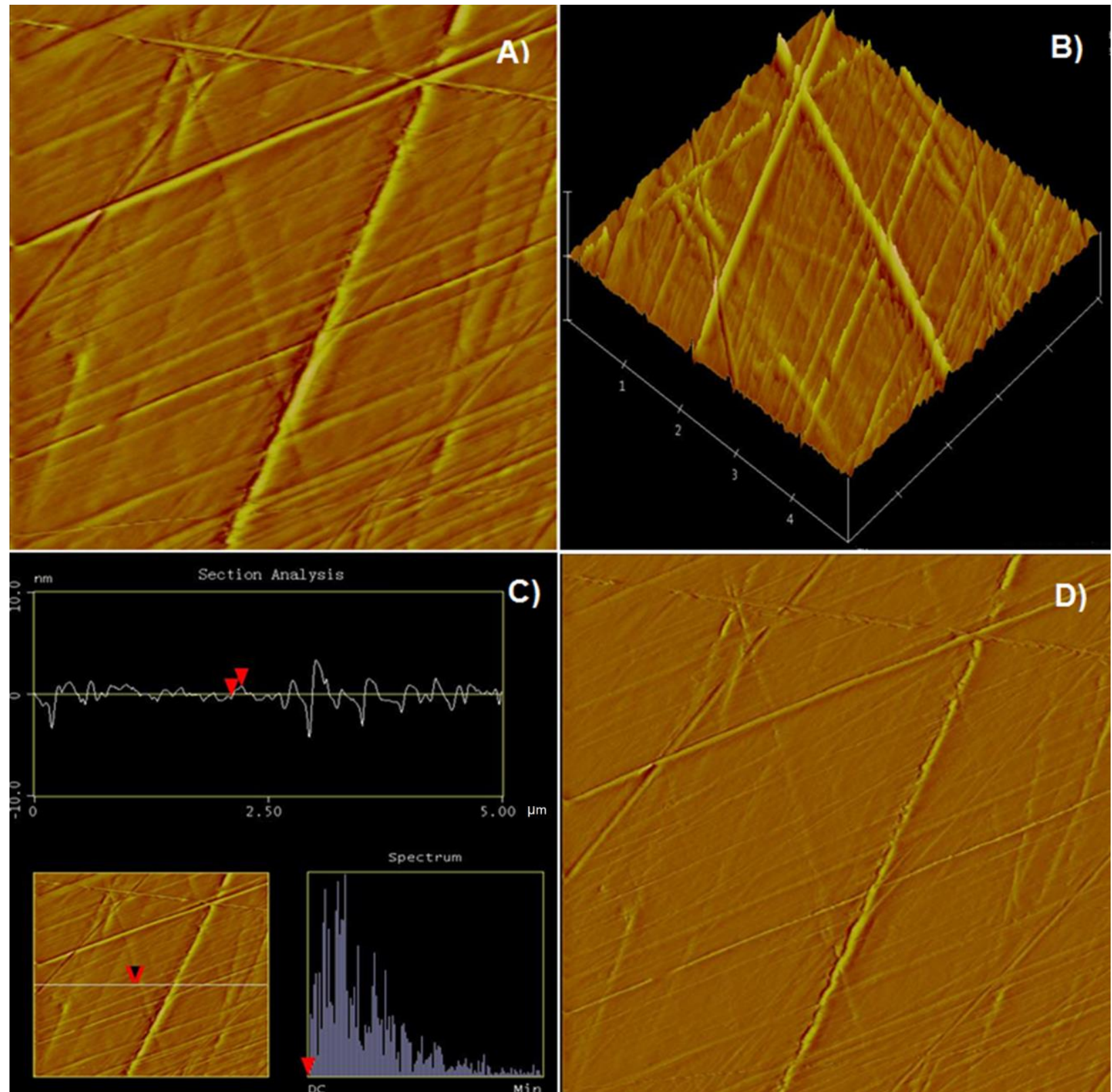

alysis

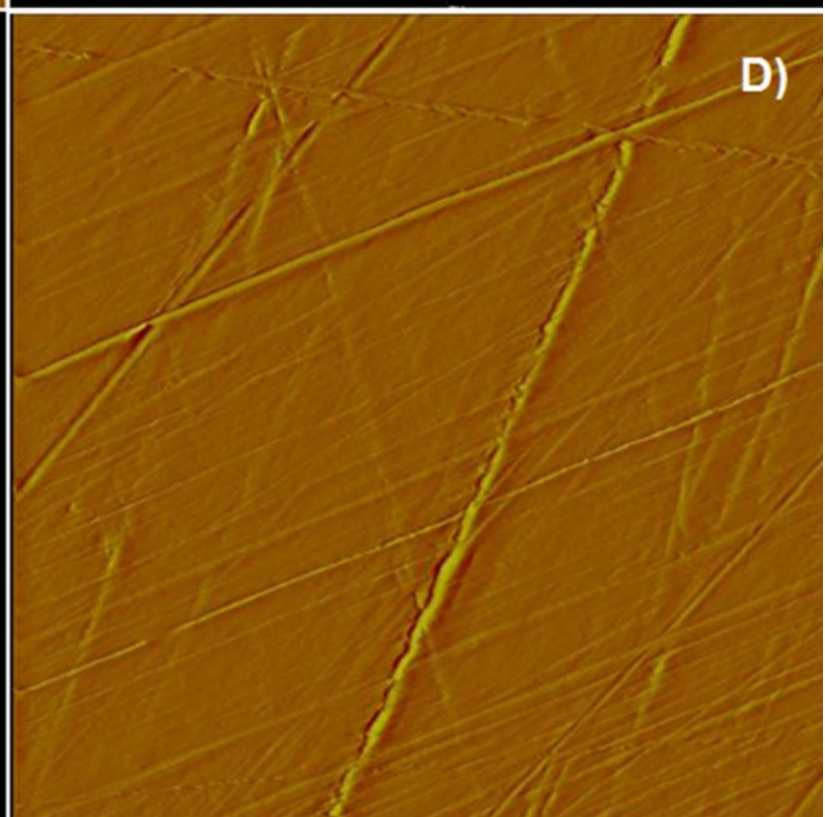

Figure 1. AFM images of a bornite surface in air. (A) The $5 \mu \mathrm{m} \times 5 \mu \mathrm{m}$ height image with a data scale of $20 \mathrm{~nm}$, (B) the 3D image, $(\mathbf{C})$ the section analysis (the red arrows indicate the top and the bottom of an average asperity) and (D) the deflection image with a data scale of $10 \mathrm{~nm}$.

Figure 2 shows the surface images of a bare bornite surface which contacted nanopure water in an AFM liquid cell for $10 \mathrm{~min}$. Figure 2A is the $10 \mu \mathrm{m} \times 10 \mu \mathrm{m}$ height image, which shows that the solid surface was still largely smooth, with little adsorbate on the sample surface detected by the AFM probe. Figure $2 B$ is the $3 \mathrm{D}$ image of Figure $2 \mathrm{~A}$. Figure $2 \mathrm{C}$ is the section analysis of Figure 2A. Figure 2D is the deflection image of Figure 2A with a $10 \mathrm{~nm}$ data scale. 

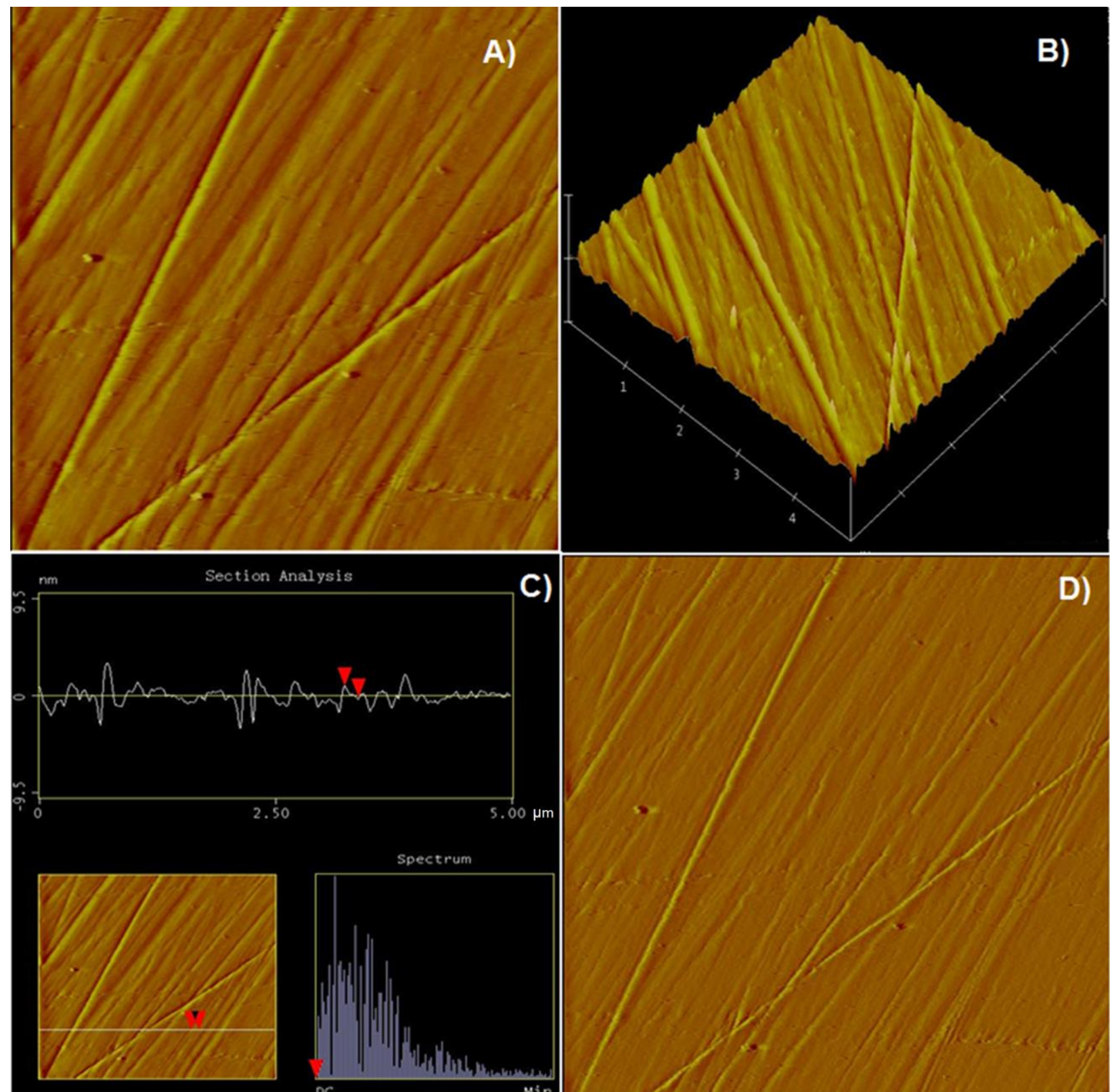

\section{)}

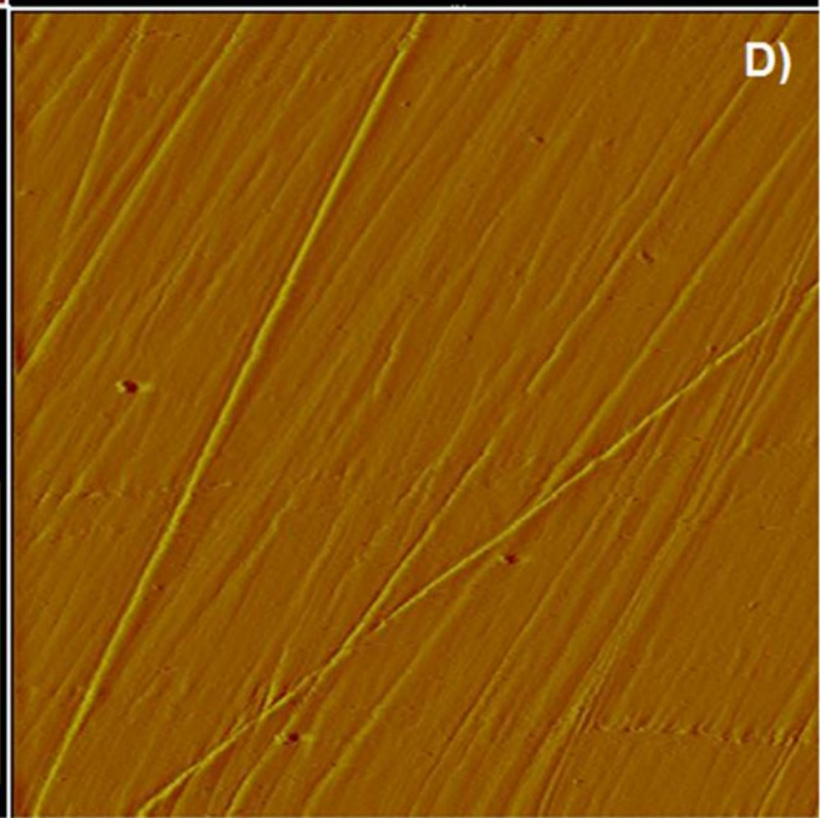

Figure 2. AFM images of a bornite surface soaked in water for $10 \mathrm{~min}$. (A) The $5 \mu \mathrm{m} \times 5 \mu \mathrm{m}$ height image with a data scale of $20 \mathrm{~nm},(\mathbf{B})$ the 3D image, (C) the section analysis (the red arrows indicate the top and the bottom of an average asperity) and $(\mathbf{D})$ the deflection image with a data scale of $10 \mathrm{~nm}$.

Figure $3 \mathrm{~A}$ is the height image of a bornite surface which contacted the $5 \times 10^{-5} \mathrm{M}$ KEX solution at $\mathrm{pH} 6$ for $10 \mathrm{~min}$. Compared to Figure 2A, a significant amount of adsorbate can be observed on the bornite when the mineral surface contacted the xanthate solution for $10 \mathrm{~min}$. Figure 3B is the 3D image of Figure 3A. Figure 3C is the section analysis of Figure $3 \mathrm{~A}$, which clearly shows that the surface roughness increased due to the adsorption. Figure $3 \mathrm{D}$ is the deflection image of Figure $3 \mathrm{~A}$ with a $10 \mathrm{~nm}$ data scale. 


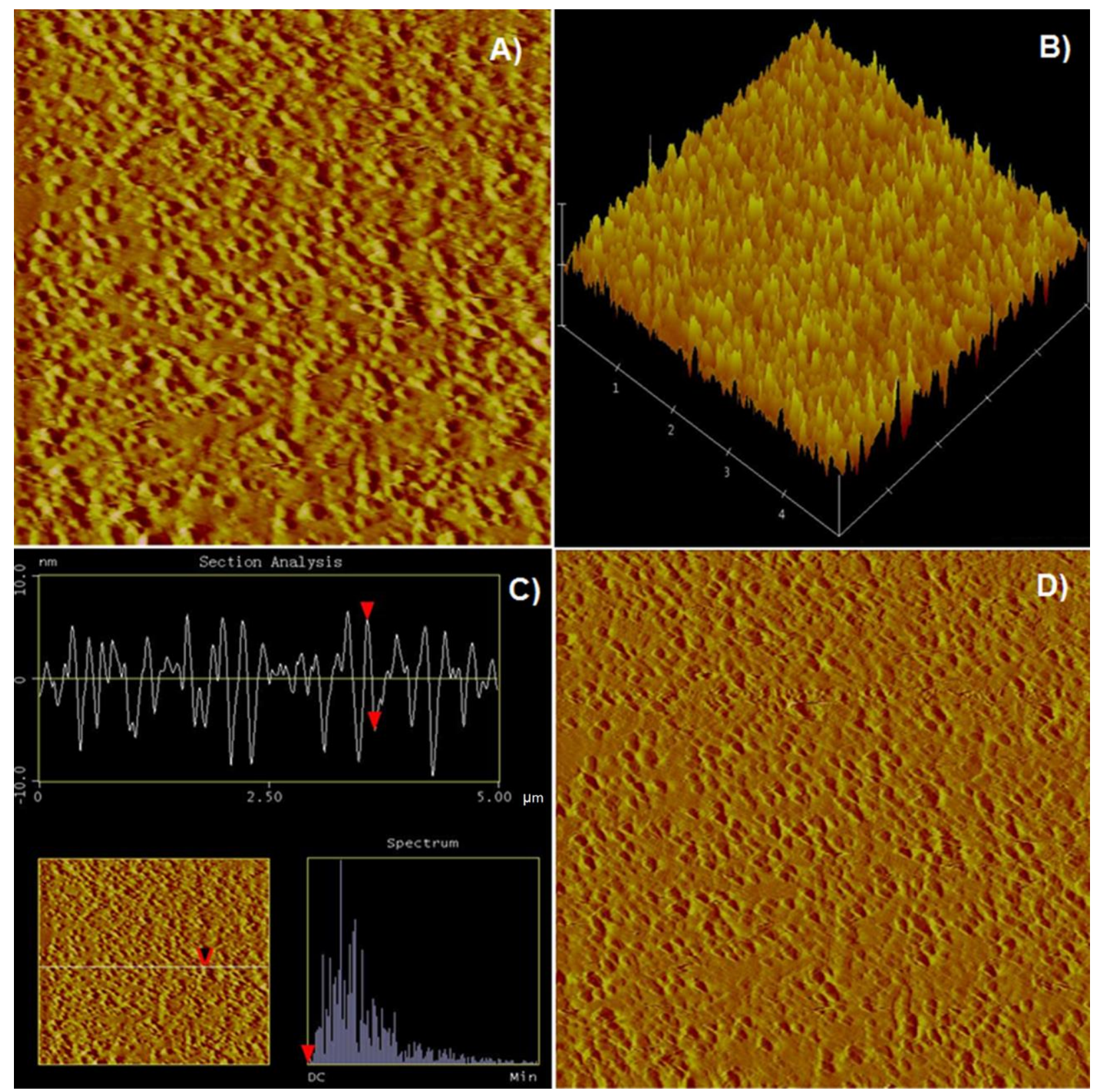

Figure 3. AFM images of a bornite surface soaked in the $5 \times 10^{-5} \mathrm{M} \mathrm{KEX}$ solution at pH 6 for $10 \mathrm{~min}$. (A) The $5 \mu \mathrm{m} \times 5 \mu \mathrm{m}$ height image with a data scale of $20 \mathrm{~nm},(\mathbf{B})$ the 3D image, (C) the section analysis (the red arrows indicate the top and the bottom of an average asperity) and (D) the deflection image with a data scale of $10 \mathrm{~nm}$.

Figure $4 \mathrm{~A}$ is the height image of a bornite surface, which was in contact with the $1 \times 10^{-4} \mathrm{M} \mathrm{KEX}$ solution at $\mathrm{pH} 6$ for $10 \mathrm{~min}$. Compared to Figure 2A, a significant amount of adsorbate can be observed on the bornite when the mineral surface contacted the $1 \times 10^{-4} \mathrm{M}$ KEX solution for $10 \mathrm{~min}$. In addition, compared to Figure 3A, the mineral surface became rougher, suggesting that more precipitates were formed at the solid/liquid interface when the KEX's concentration increased from $5 \times 10^{-5} \mathrm{M}$ to $1 \times 10^{-4} \mathrm{M}$. Figure $4 \mathrm{~B}$ is the 3D image of Figure $4 \mathrm{~A}$. Figure $4 \mathrm{C}$ is the section analysis of Figure $4 \mathrm{~A}$, which confirms that the surface roughness increased due to the adsorption of the collector. Figure $4 \mathrm{D}$ is the deflection image of Figure $4 \mathrm{~A}$ with a $10 \mathrm{~nm}$ data scale. 

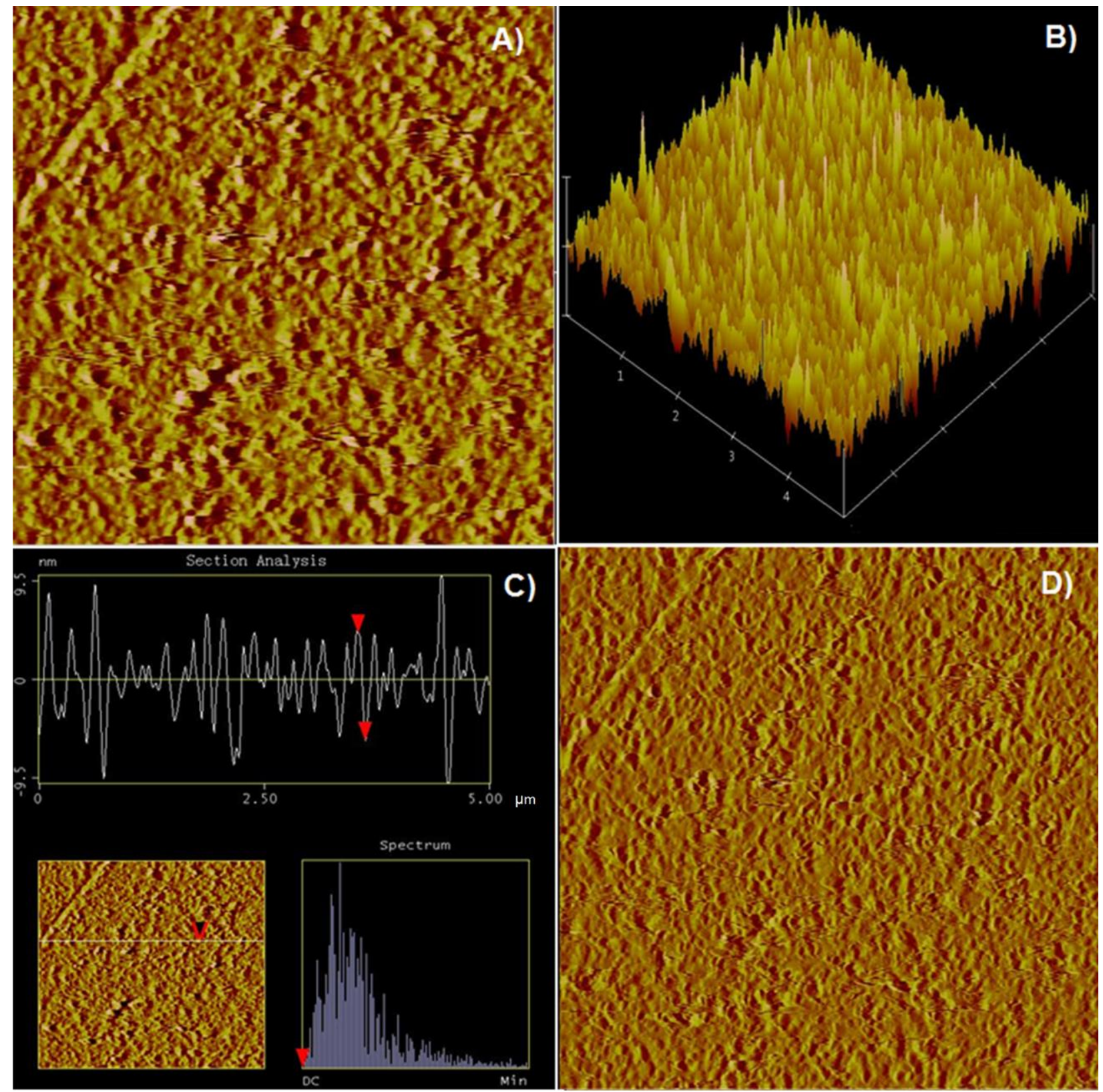

Figure 4. AFM images of a bornite surface soaked in the $1 \times 10^{-4} \mathrm{M} \mathrm{KEX} \mathrm{solution} \mathrm{at} \mathrm{pH} 6$ for $10 \mathrm{~min}$. (A) The $5 \mu \mathrm{m} \times 5 \mu \mathrm{m}$ height image with a data scale of $20 \mathrm{~nm},(\mathbf{B})$ the 3D image, (C) the section analysis (the red arrows indicate the top and the bottom of an average asperity) and (D) the deflection image with a data scale of $10 \mathrm{~nm}$.

Figure 5A is the height image of a bornite surface soaked in the $1 \times 10^{-4} \mathrm{M} \mathrm{KEX}$ solution at $\mathrm{pH} 6$ for $20 \mathrm{~min}$ and further rinsed with $10 \mathrm{~mL}$ ethanol and $10 \mathrm{~mL}$ water consecutively. The images were finally obtained when the mineral sample contacted the water. Compared to Figure 4A, it can be observed that the precipitates, as observed from Figure $4 \mathrm{~A}$, still existed on the bornite surface, and were not dissolved or rinsed off the mineral surface. Figure $5 \mathrm{~B}$ is the $3 \mathrm{D}$ image of Figure $5 \mathrm{~A}$. Figure $5 \mathrm{C}$ is the section analysis of Figure 5A. Figure 5D is the deflection image of Figure 5A with a $10 \mathrm{~nm}$ data scale. 

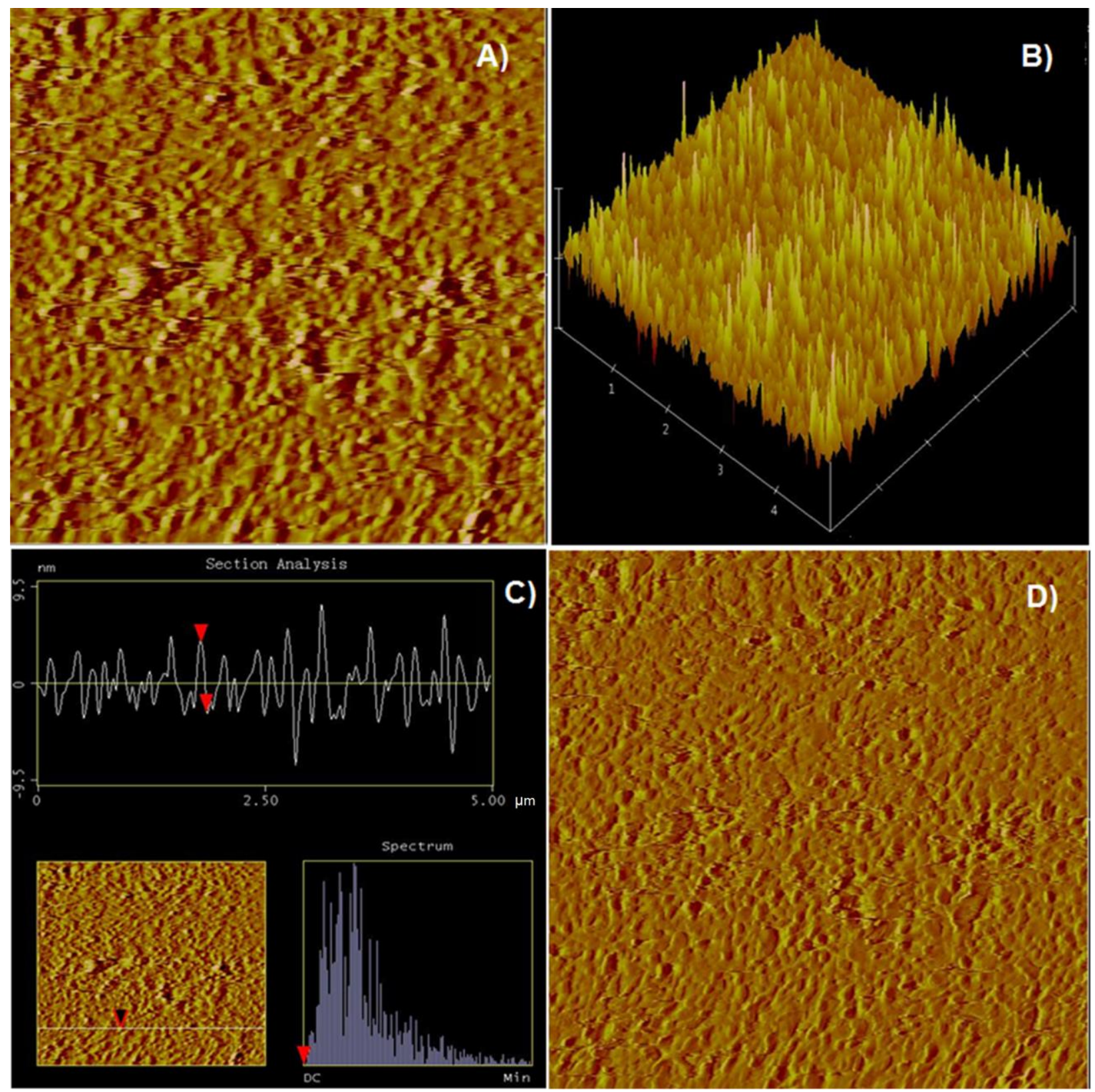

Figure 5. AFM images of a bornite surface soaked in the $1 \times 10^{-4} \mathrm{M} \mathrm{KEX} \mathrm{solution} \mathrm{at} \mathrm{pH} 6$ for 20 min and further rinsed with ethanol and water. (A) The $5 \mu \mathrm{m} \times 5 \mu \mathrm{m}$ height image with a data scale of $20 \mathrm{~nm},($ B) the 3D image, (C) the section analysis (the red arrows indicate the top and the bottom of an average asperity) and (D) the deflection image with a data scale of $10 \mathrm{~nm}$.

Figure 6 shows the AFM images of a bornite surface soaked in the $5 \times 10^{-4} \mathrm{M}$ KEX solution at $\mathrm{pH} 6$ for $10 \mathrm{~min}$. By comparing Figure 6A, the height image, to Figure 2A, a significant amount of bornite can be observed after the mineral surface contacted the xanthate solution. In addition, comparing Figure $6 \mathrm{~A}$ to Figures $3 \mathrm{~A}$ and $4 \mathrm{~A}$, when the KEX's concentration increased, more precipitates formed at the solid/liquid interface, and the mineral surface became much rougher. Figure $6 \mathrm{~B}$ is the 3D image of Figure $6 \mathrm{~A}$. Figure $6 \mathrm{C}$, the section analysis of Figure $6 \mathrm{~A}$, confirms that the surface roughness increased greatly when the bornite surface contacted a high concentration of KEX. Figure $6 \mathrm{D}$ is the deflection image of Figure 6A with a $10 \mathrm{~nm}$ data scale. 

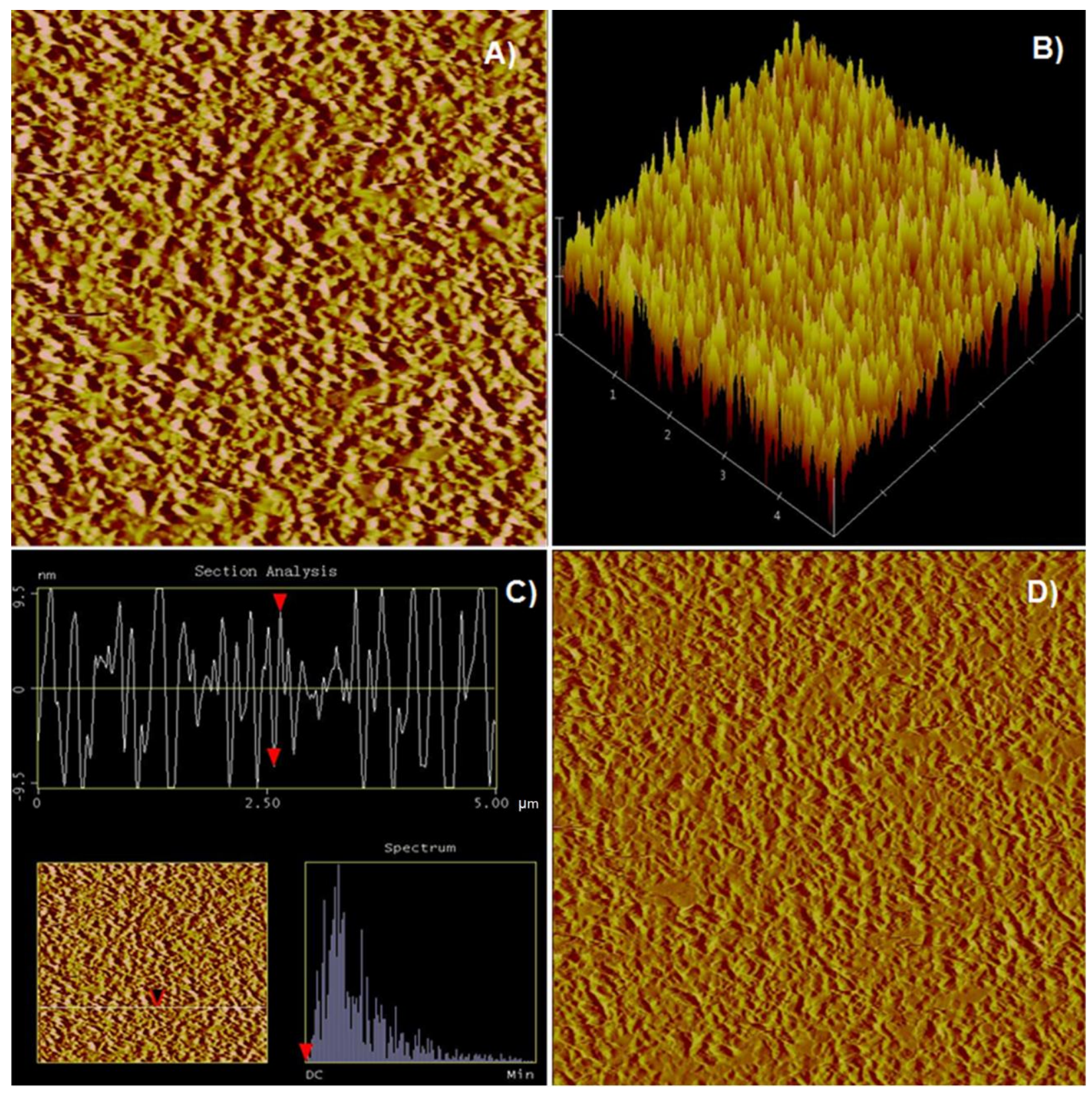

Figure 6. AFM images of a bornite surface soaked in the $5 \times 10^{-4} \mathrm{M} \mathrm{KEX} \mathrm{solution} \mathrm{at} \mathrm{pH} 6$ for $10 \mathrm{~min}$. (A) The $5 \mu \mathrm{m} \times 5 \mu \mathrm{m}$ height image with a data scale of $20 \mathrm{~nm},(\mathbf{B})$ the 3D image, (C) the section analysis (the red arrows indicate the top and the bottom of an average asperity) and (D) the deflection image with a data scale of $10 \mathrm{~nm}$.

To verify the adsorption of the KEX on bornite in the solution, after Figure 6 was obtained, a $3 \mu \mathrm{m} \times 3 \mu \mathrm{m}$ area was scanned once, applying a much larger scan force to intentionally remove the adsorbate. Further, the same position was scanned again in a $5 \mu \mathrm{m} \times 5 \mu \mathrm{m}$ area, applying a normal scan force. The result is shown in Figure 7. From Figure 7A, the height image, a $3 \mu \mathrm{m} \times 3 \mu \mathrm{m}$ 'window' can be observed in the center of the image due to the removal of some adsorbate from mineral surface under the previously applied large scan force. That is, the 'window' in the center with a low profile is the bornite surface covered by the adsorbate, which was partially removed by the applied large scan force. The surrounding area with a high profile is the mineral surface covered by the adsorbate, which was not disturbed by the large scan force. By comparing Figure 7B, the 3D image of Figure 7A, to Figure 6B, a pit on the mineral surface can be easily observed, with adsorbate covering the surrounding area. Figure 7C, the section analysis of Figure 7A, shows the height difference between the 
'window' (as shown by the green markers) and the surrounding area being covered with adsorbate (as shown by the red markers). Figure 7D is the deflection image of Figure 7A with a $10 \mathrm{~nm}$ data scale.

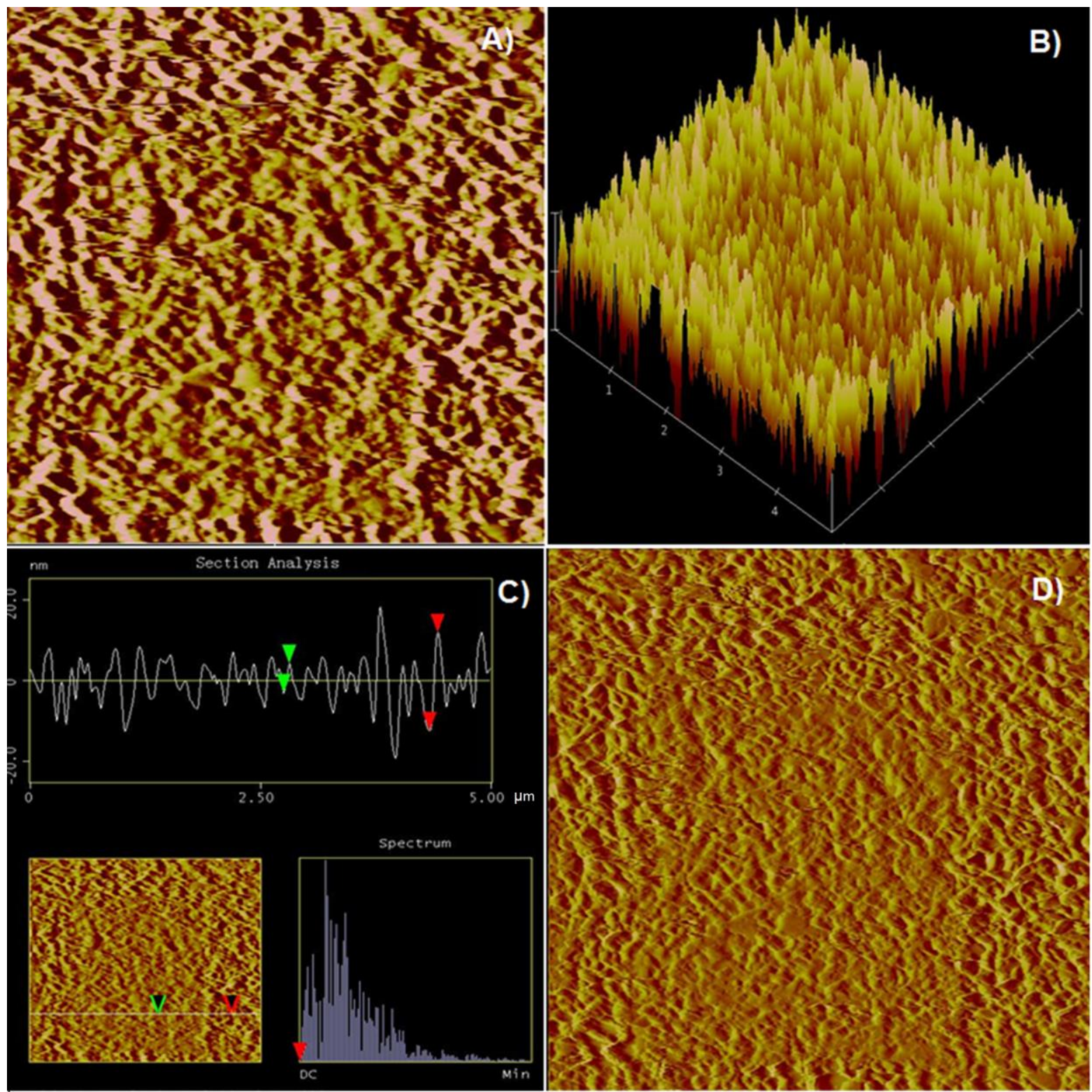

Figure 7. AFM images of a bornite surface soaked in the $5 \times 10^{-4} \mathrm{M} \mathrm{KEX}$ solution at $\mathrm{pH} 6$ for $20 \mathrm{~min}$. (A) The $5 \mu \mathrm{m} \times 5 \mu \mathrm{m}$ height image with a data scale of $20 \mathrm{~nm},(\mathbf{B})$ the 3D image, (C) the section analysis and (D) the deflection image with a data scale of $10 \mathrm{~nm}$.

Figure 8 shows the AFM images of a bornite surface soaked in the $1 \times 10^{-5} \mathrm{M}$ PAX solution at $\mathrm{pH} 6$ for $10 \mathrm{~min}$. By comparing Figure $8 \mathrm{~A}$, the height image, to Figure $2 \mathrm{~A}$, some precipitates can be observed on the bornite when the mineral surface contacted the PAX solution. Figure $8 \mathrm{~B}$ is the $3 \mathrm{D}$ image of Figure $8 \mathrm{~A}$. Figure $8 \mathrm{C}$, the section analysis of Figure $8 \mathrm{~A}$, shows that the surface roughness increased due to the adsorption of PAX. Figure $8 \mathrm{D}$ is the deflection image of Figure $8 \mathrm{~A}$ with a $10 \mathrm{~nm}$ data scale. 

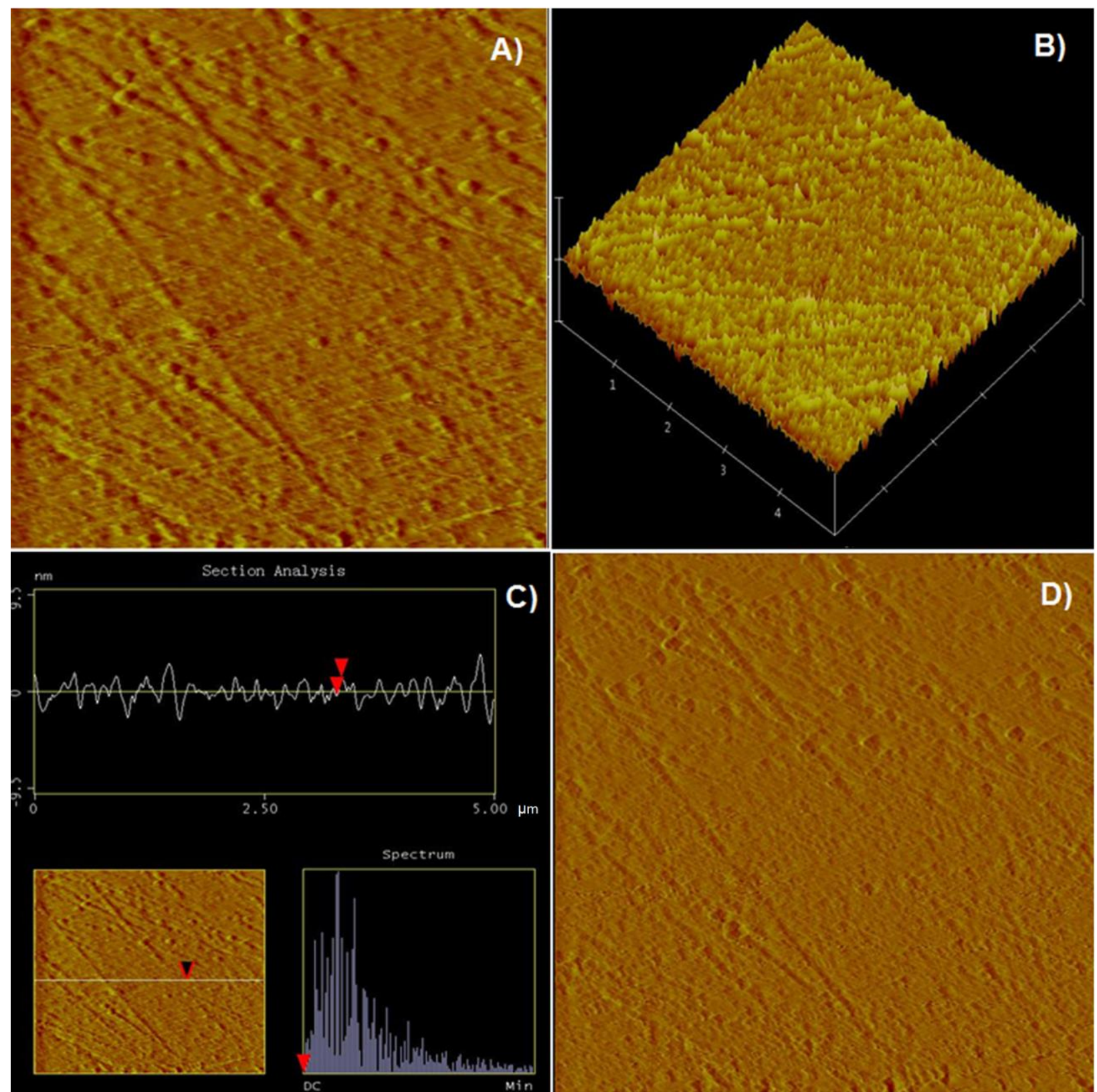

Figure 8. AFM images of a bornite surface soaked in the $1 \times 10^{-5} \mathrm{M}$ PAX solution at pH 6 for $10 \mathrm{~min}$. (A) The $5 \mu \mathrm{m} \times 5 \mu \mathrm{m}$ height image with a data scale of $20 \mathrm{~nm},(\mathbf{B})$ the 3D image, $(\mathbf{C})$ the section analysis (the red arrows indicate the top and the bottom of an average asperity) and (D) the deflection image with a data scale of $10 \mathrm{~nm}$.

Figure 9 shows the AFM images of a bornite surface soaked in $5 \times 10^{-5} \mathrm{M}$ PAX solution at $\mathrm{pH} 6$ for $10 \mathrm{~min}$. By comparing Figure 9A, the height image, to Figure 2A, a significant amount of adsorbate can be observed on the bornite when the mineral surface contacted the $5 \times 10^{-5} \mathrm{M}$ PAX solution for $10 \mathrm{~min}$. By comparing Figure $9 \mathrm{~A}$ to Figure $8 \mathrm{~A}$, it can be seen that, when the PAX concentration increased from $1 \times 10^{-5} \mathrm{M}$ to $5 \times 10^{-5} \mathrm{M}$, the mineral surface became much rougher, with more precipitates forming at the solid/liquid interface. Figure $9 \mathrm{~B}$ is the 3D image of Figure $9 \mathrm{~A}$. Figure $9 \mathrm{C}$ is the section analysis of Figure 9A, which confirms that the surface roughness increased with the increasing PAX concentration. Figure 9D is the deflection image of Figure 9A with a $10 \mathrm{~nm}$ data scale. 

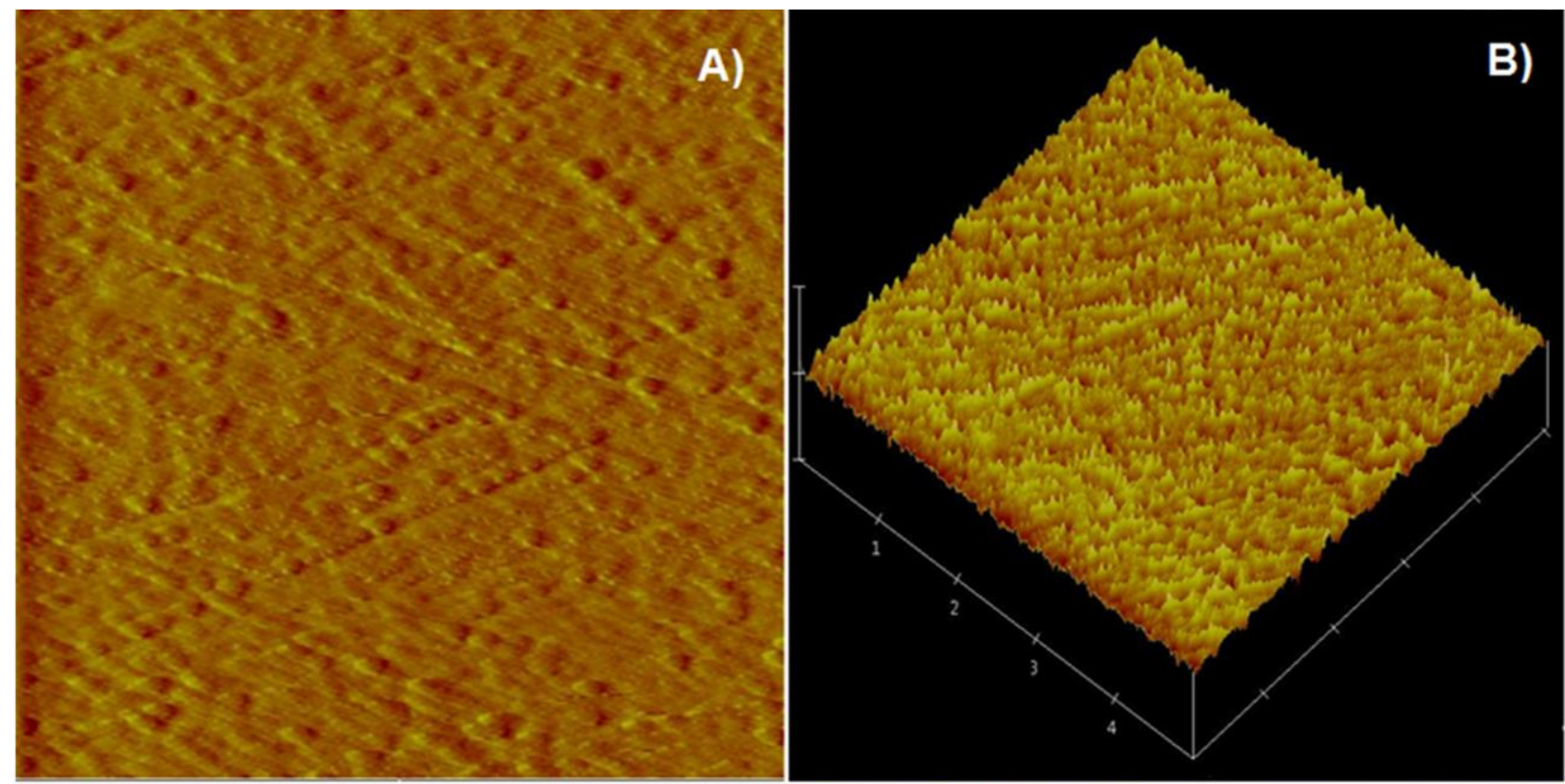

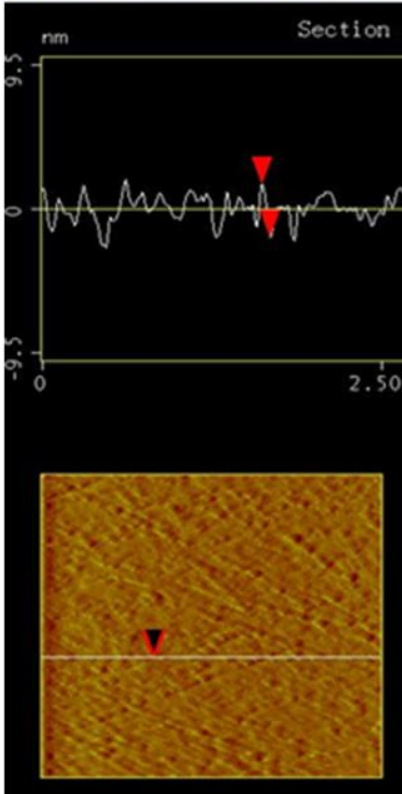

50

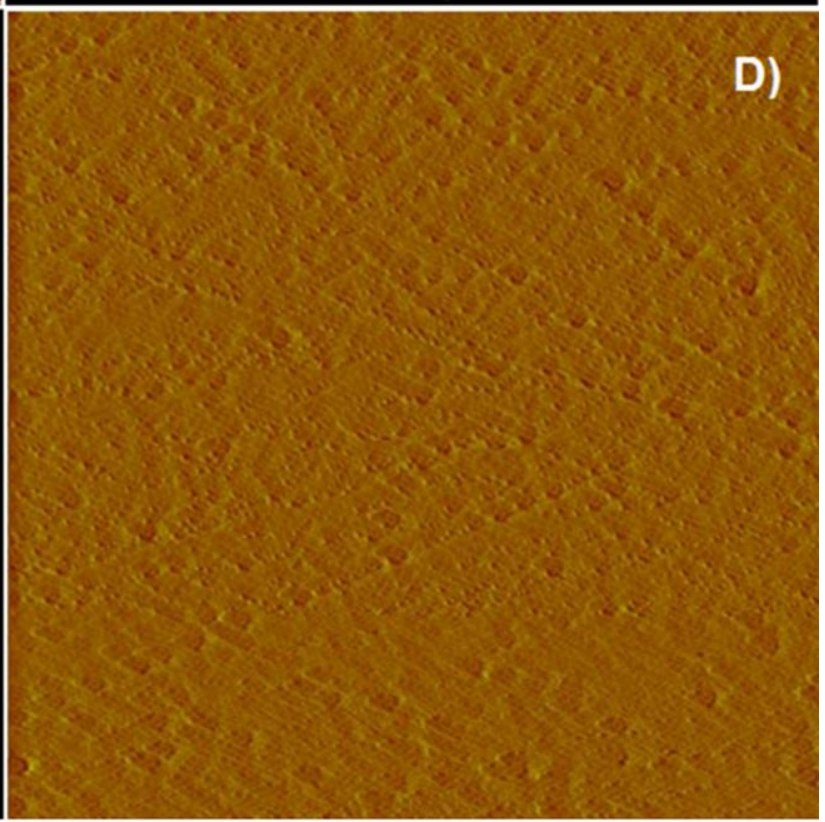

Figure 9. AFM images of a bornite surface soaked in the $5 \times 10^{-5} \mathrm{M}$ PAX solution at $\mathrm{pH} 6$ for $10 \mathrm{~min}$. (A) The $5 \mu \mathrm{m} \times 5 \mu \mathrm{m}$ height image with a data scale of $20 \mathrm{~nm}$, (B) the 3D image, (C) the section analysis (the red arrows indicate the top and the bottom of an average asperity) and (D) the deflection image with a data scale of $10 \mathrm{~nm}$.

Figure 10 shows the AFM images of a bornite surface soaked in the $1 \times 10^{-4} \mathrm{M}$ PAX solution at $\mathrm{pH} 6$ for $10 \mathrm{~min}$. By comparing Figure 10A, the height image, to Figure 2A, a significant amount of adsorbate can be observed on the bornite when the mineral surface contacted the $1 \times 10^{-4} \mathrm{M}$ PAX solution for $10 \mathrm{~min}$. By comparing Figure $10 \mathrm{~A}$ to Figures $8 \mathrm{~A}$ and $9 \mathrm{~A}$, when the PAX concentration increases, the mineral surface became much rougher, with more precipitates forming at the solid/liquid interface. Figure 10B is the 3D image of Figure 10A. Figure 10C, the section analysis of Figure 10A, shows that the surface roughness increased with the increasing PAX concentration. Figure 10D is the deflection image of Figure 10A with a $10 \mathrm{~nm}$ data scale. 

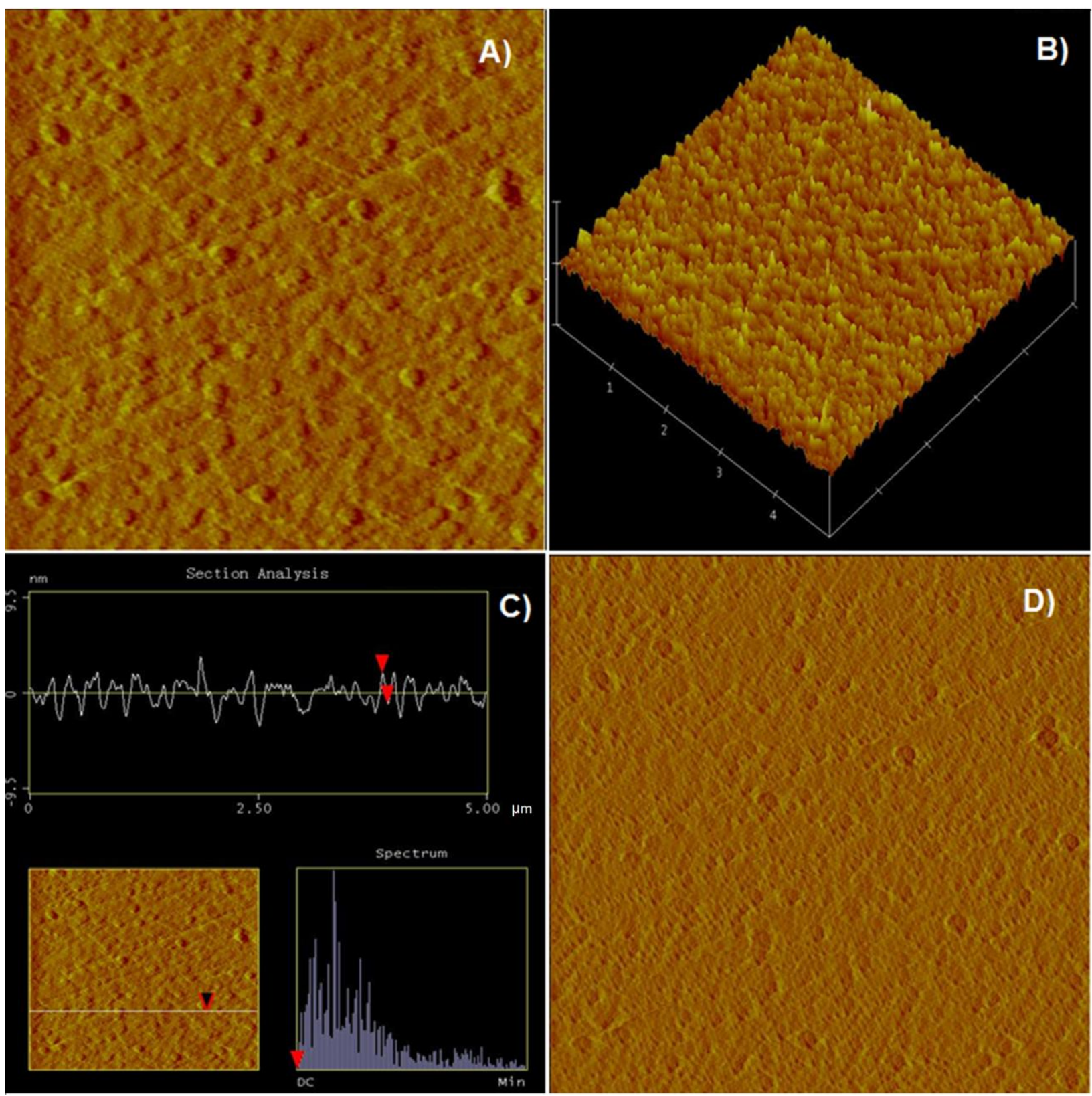

Figure 10. AFM images of a bornite surface soaked in the $1 \times 10^{-4} \mathrm{M}$ PAX solution at pH 6 for $10 \mathrm{~min}$. (A) The $5 \mu \mathrm{m} \times 5 \mu \mathrm{m}$ height image with a data scale of $20 \mathrm{~nm},(\mathbf{B})$ the 3D image, (C) the section analysis (the red arrows indicate the top and the bottom of an average asperity) and (D) the deflection image with a data scale of $10 \mathrm{~nm}$.

To verify the adsorption of the PAX on bornite in the solution, after Figure 10 was obtained, a $2 \mu \mathrm{m} \times 2 \mu \mathrm{m}$ area was scanned once, applying a much larger scan force to intentionally remove the adsorbate. Further, the same position was scanned again in a $5 \mu \mathrm{m} \times 5 \mu \mathrm{m}$ area, applying a normal scan force. The result is shown as Figure 11. As shown in Figure 11A, the height image, a $2 \mu \mathrm{m} \times 2 \mu \mathrm{m}$ 'window' is shown in the center of the image due to the partial removal of the adsorbate from the mineral surface under the previously applied large scan force. That is, the 'window' in the center with a low profile is the bornite surface covered by the adsorbate, which was partially removed by the applied large scan force. The surrounding area with a high profile is the mineral surface covered by the adsorbate, which was not disturbed by the large scan force. This finding is as that shown in Figure 7. By comparing Figure 11B, the 3D image of Figure 11A, to Figure 10B, a pit on mineral surface can be easily observed, with adsorbate covering the surrounding 
area. Figure $11 \mathrm{C}$ is the section analysis of Figure $11 \mathrm{~A}$, which shows the height difference between the 'window' and the surrounding area covered with adsorbate (indicated by the red markers). Figure 11D is the deflection image of Figure $11 \mathrm{~A}$ with a $10 \mathrm{~nm}$ data scale. The adsorbate strongly combined with the mineral surface strongly, and a quite large scan force had to be applied during the experiment. Therefore, the obtained 'window' was slightly deformed, as shown in Figure 11A.
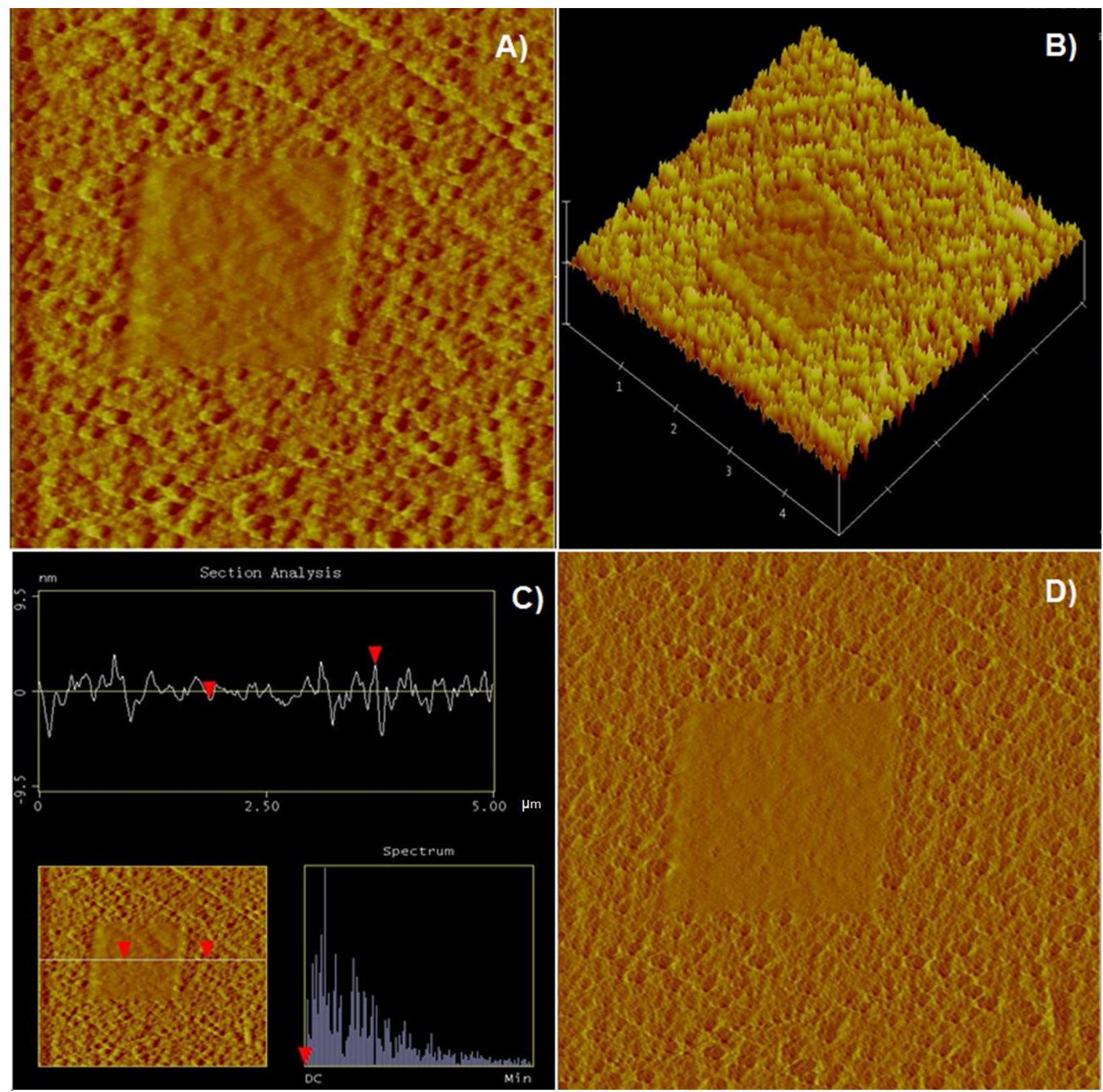

Figure 11. AFM images of a bornite surface soaked in $1 \times 10^{-4} \mathrm{M}$ PAX solution at pH 6 for $20 \mathrm{~min}$. (A) The $5 \mu \mathrm{m} \times 5 \mu \mathrm{m}$ height image with a data scale of $20 \mathrm{~nm},(\mathbf{B})$ the 3D image, (C) the section analysis and (D) the deflection image with a data scale of $10 \mathrm{~nm}$. The $2 \mu \mathrm{m} \times 2 \mu \mathrm{m}$ blank 'window' in the center of the image occurred due to the removal of the adsorbate from the mineral surface under the intentionally applied large scan force.

Figure 12 shows the AFM images of a bornite surface soaked in the $5 \times 10^{-4} \mathrm{M} \mathrm{KEX}$ solution at $\mathrm{pH} 10$. Figure $12 \mathrm{~A}-\mathrm{C}$ are the height images with a $20 \mathrm{~nm}$ data scale obtained after the mineral surface contacted the KEX solution, respectively, for 5, 10 and $20 \mathrm{~min}$. Similar to Figure 6, in all the images, a significant amount of adsorbate can be observed on 
the bornite. Figure 12D is the $1 \mu \mathrm{m} \times 1 \mu \mathrm{m}$ (large magnification) height image collected right after Figure $12 \mathrm{C}$ was obtained.
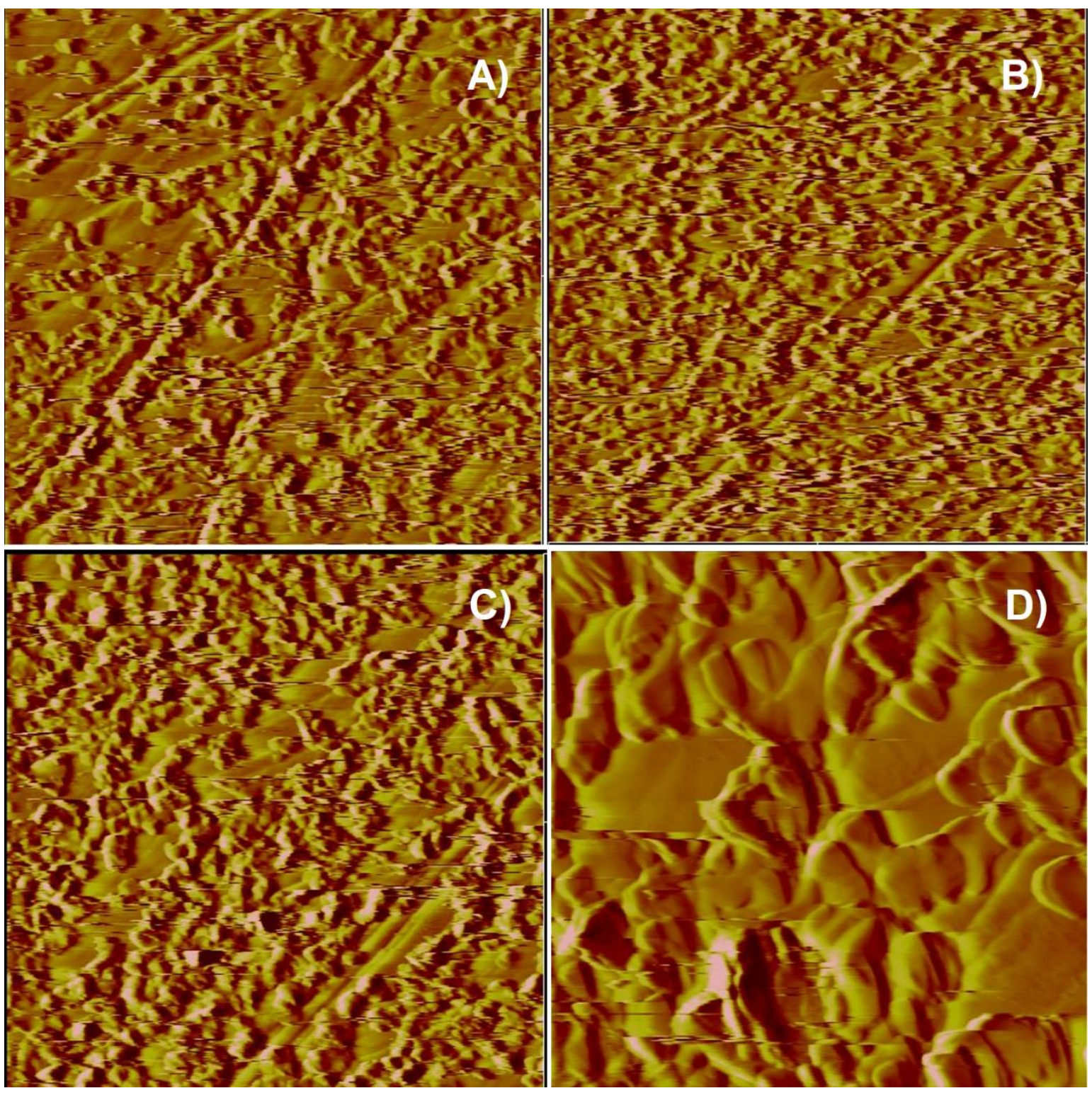

Figure 12. AFM height images $(5 \mu \mathrm{m} \times 5 \mu \mathrm{m})$ with a data scale of $20 \mathrm{~nm}$ of a bornite surface soaked in the $5 \times 10^{-4} \mathrm{M} \mathrm{KEX}$ solution at $\mathrm{pH} 10$ (A) for $5 \mathrm{~min},(\mathbf{B})$ for $10 \mathrm{~min}$, (C) for $20 \mathrm{~min}$ and (D) for $20 \mathrm{~min}(1 \mu \mathrm{m} \times 1 \mu \mathrm{m})$.

Figure 13 shows the AFM images of a bornite surface soaked in the $1 \times 10^{-4}$ M PAX solution at $\mathrm{pH} 10$. Figure $13 \mathrm{~A}-\mathrm{C}$ are the height images with a $20 \mathrm{~nm}$ data scale obtained after the mineral surface contacted the PAX solution, respectively, for 5, 10 and $20 \mathrm{~min}$. Similar to Figure 10, in all the images, a significant amount of adsorbate can be observed on the bornite. Figure 13D is the $1 \mu \mathrm{m} \times 1 \mu \mathrm{m}$ (large magnification) height image collected right after Figure $13 \mathrm{C}$ was obtained. 


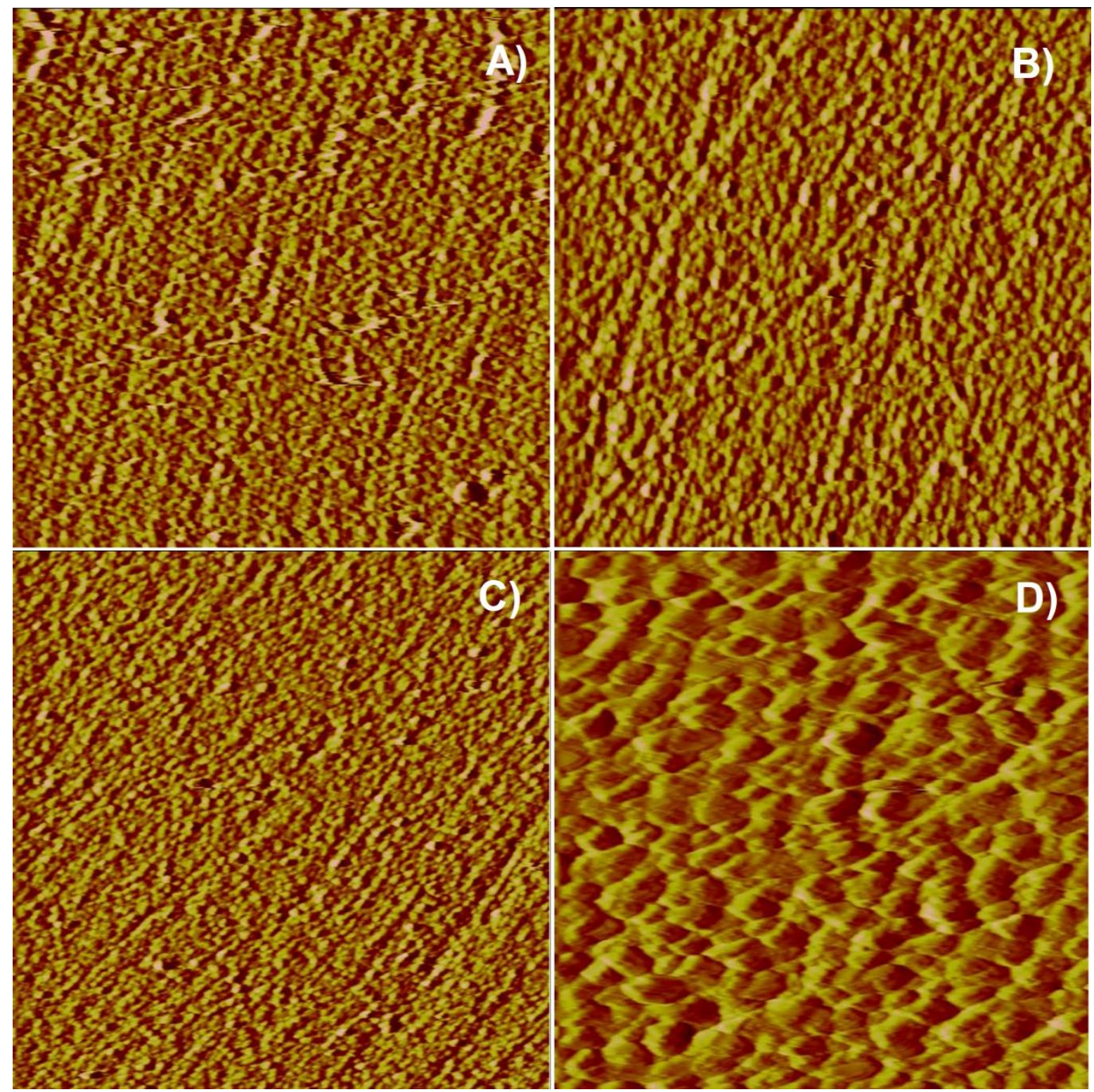

Figure 13. AFM height images $(5 \mu \mathrm{m} \times 5 \mu \mathrm{m})$ with a data scale of $20 \mathrm{~nm}$ of a bornite surface soaked in the $1 \times 10^{-4} \mathrm{M}$ PAX solution at $\mathrm{pH} 10$ (A) for $5 \mathrm{~min},(\mathbf{B})$ for $10 \mathrm{~min}$, (C) for $20 \mathrm{~min}$ and (D) for $20 \mathrm{~min}(1 \mu \mathrm{m} \times 1 \mu \mathrm{m})$.

To clearly show the difference of the adsorbate in the morphologies of bornite and chalcopyrite, the adsorption of xanthate on chalcopyrite was also studied, and the AFM image is shown in Figure 14. Figure 14A,B were obtained with $5 \times 10^{-4} \mathrm{M}$ KEX. Figure 14C,D were obtained with $5 \times 10^{-5}$ M PAX. The AFM images clearly show that there was patch-like adsorbate on the chalcopyrite surface, which was flat with smooth and round edges. This morphology fits well with the fact that oily dialkyl dixanthogen is generally insoluble in water, and the circular boundary is the direct result of the high interfacial tension between the hydrophobic dixanthogen and water $[17,18]$. In addition, this adsorbate had a completely different morphology as the one shown in Figures 3-13. 

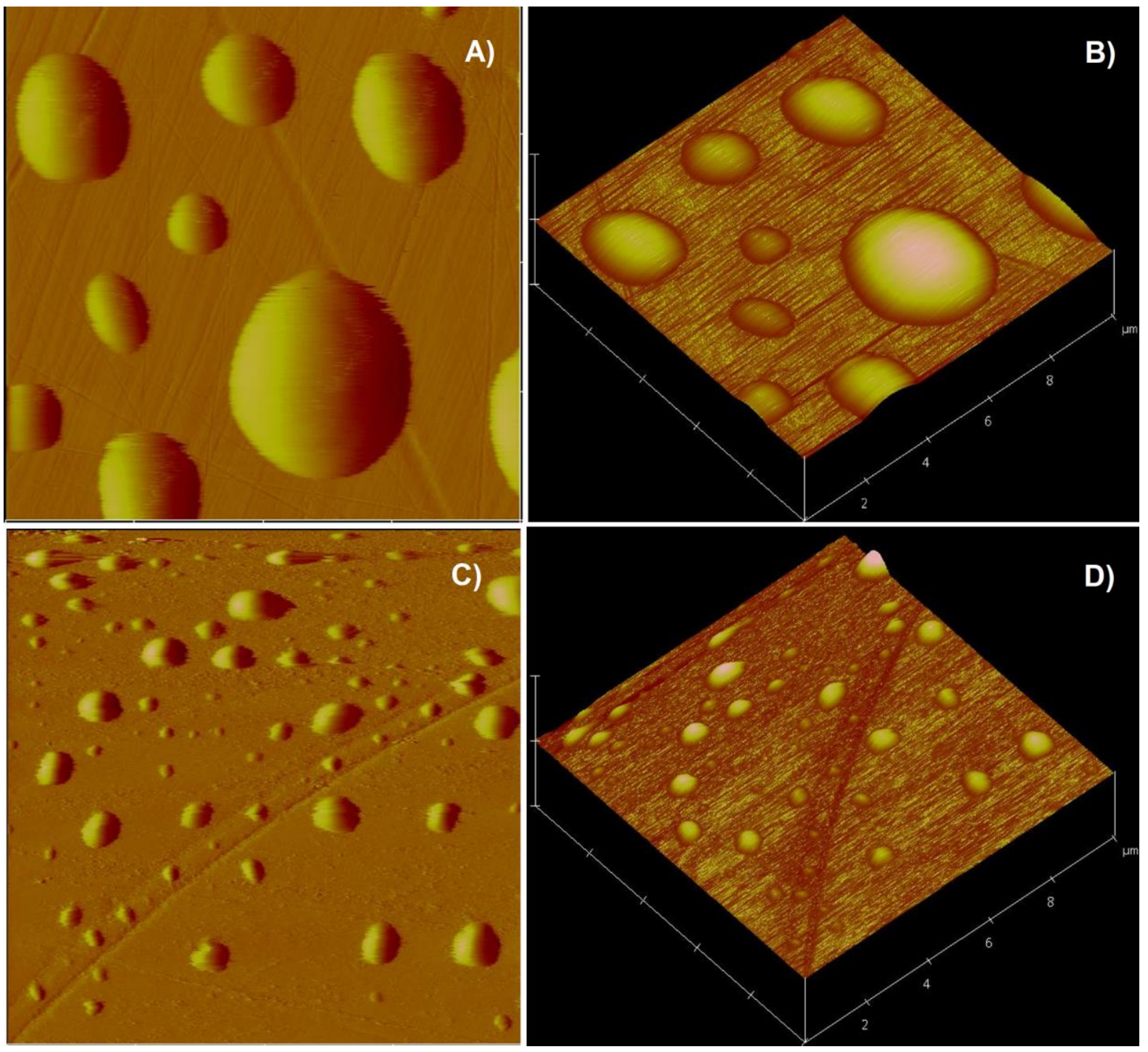

Figure 14. AFM images of a chalcopyrite surface in the xanthate solution at pH 6 for $30 \mathrm{~min}$. (A) The $10 \mu \mathrm{m} \times 10 \mu \mathrm{m}$ deflection image with a data scale of $200 \mathrm{~nm}$ at $5 \times 10^{-4} \mathrm{M} \mathrm{KEX,(B)}$ the $3 \mathrm{D}$ image of $(\mathbf{A}),(\mathbf{C})$ the $10 \mu \mathrm{m} \times 10 \mu \mathrm{m}$ deflection image with a data scale of $200 \mathrm{~nm}$ at $5 \times 10^{-5} \mathrm{M}$ PAX and (D) the 3D image of (C).

\subsection{AFM Surface Force Measurement}

The interaction force (F) between an AFM probe and a polished bornite plate is measured when the plate contacts various PAX solutions at $\mathrm{pH} 6$ for $10 \mathrm{~min}$. Using an AFM force measurement, one can obtain both the approach force curve and the retract force curve, which are shown as Figures 15 and 16, respectively. 


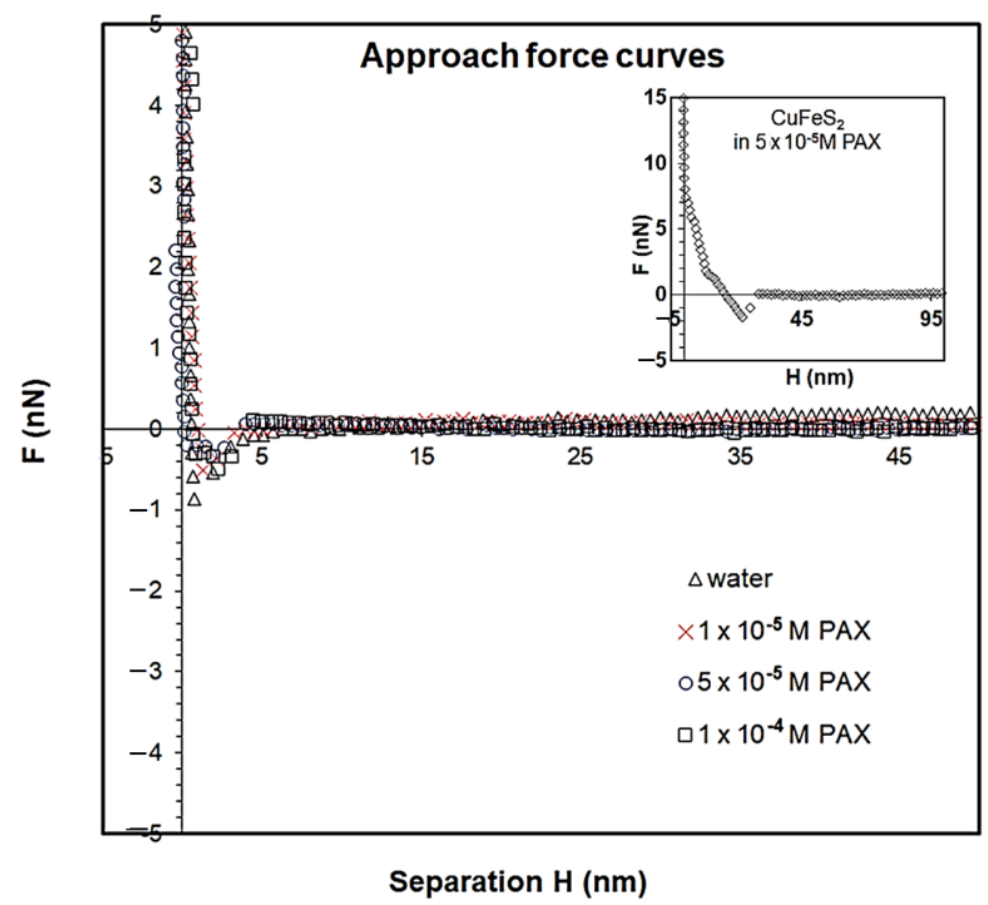

Figure 15. The approach force (F) measured between an AFM probe and a bornite plate soaked in solutions at $\mathrm{pH} 6$ as a function of the separation $(\mathrm{H})$ between the probe and the plate by applying an AFM force measurement. $(\Delta)$ in water; $(\times)$ in the $1 \times 10^{-5} \mathrm{M}$ PAX solution, (o) in the $5 \times 10^{-5} \mathrm{M}$ PAX solution and $(\square)$ in the $1 \times 10^{-4}$ M PAX solution. The inlet $(\diamond)$ shows the approach force curve obtained with $\mathrm{CuFeS}_{2}$ in the $5 \times 10^{-5} \mathrm{M}$ PAX solution.

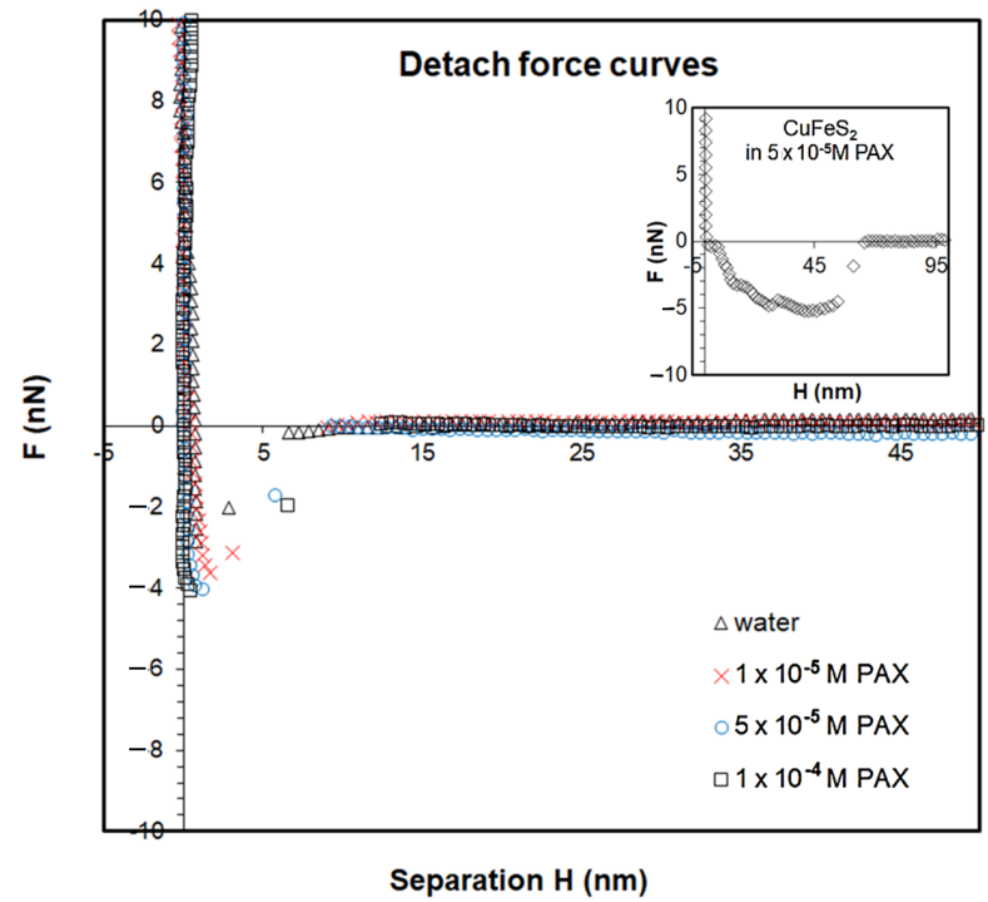

Figure 16. The detach force (F) measured between an AFM probe and a bornite plate soaked in solutions at $\mathrm{pH} 6$ as a function of the separation $(\mathrm{H})$ between the probe and the plate by applying an AFM force measurement. $(\Delta)$ in water, $(\times)$ in the $1 \times 10^{-5} \mathrm{M}$ PAX solution, (o) in the $5 \times 10^{-5} \mathrm{M}$ PAX solution and $(\square)$ in the $1 \times 10^{-4}$ M PAX solution. The inlet $(\diamond)$ shows the detach force curve obtained with $\mathrm{CuFeS}_{2}$ in the $5 \times 10^{-5} \mathrm{M}$ PAX solution. 
Figure 15 shows that the approach force curves measured in water and various PAX solutions were similar to each other. The "jump-in" occurred where the separation was less than $5 \mathrm{~nm}$, which was within the range of the van der Waals force. Figure 16 shows that the detach force measured between an AFM probe and bornite surface in water was about $3 \mathrm{nN}$. The value increased slightly to $4 \mathrm{nN}$ when in the $1 \times 10^{-5} \mathrm{M}$ PAX solution. Further increasing the concentration of the PAX solution did not significantly change the detach force. The fact that the "jump-off" point was sharp and that the "jump-off" point occurred where the separation was close to $0 \mathrm{~nm}$ suggest that the adsorbate is physically rigid in nature. The inlet shows the detach force curve obtained with $\mathrm{CuFeS}_{2}$ in $5 \times 10^{-5} \mathrm{M}$ PAX solution, and the detach force was about $5.2 \mathrm{nN}$. The fact that the "jump-off" point was not sharp and that the "jump-off" point occurred at above $50 \mathrm{~nm}$ confirms that the oily dixanthogen is deformable.

\subsection{AFT-FTIR Results}

Figure 17 shows the ATR-FTIR spectra of the adsorbate on bornite after the mineral surface $5 \times 10^{-4} \mathrm{M} \mathrm{KEX}$ solution at $\mathrm{pH} 6$ for $1 \mathrm{~h}$. On the spectra, the main peaks shown at $1195 \mathrm{~cm}^{-1}$ and $1126 \mathrm{~cm}^{-1}$ were due to the bonds of C-O-C, and the peaks at $1049 \mathrm{~cm}^{-1}$ and $1032 \mathrm{~cm}^{-1}$ were due to the bonds of S-C-S. The results are in line with the FTIR spectra of cuprous xanthate as reported by Poling [23] and Leppinen et al. [24]. That is, the obtained FTIR spectra, as shown in Figure 17, confirms that the adsorbate on bornite in xanthate solutions is essentially $\mathrm{CuX}$, with no dixanthogen detected.

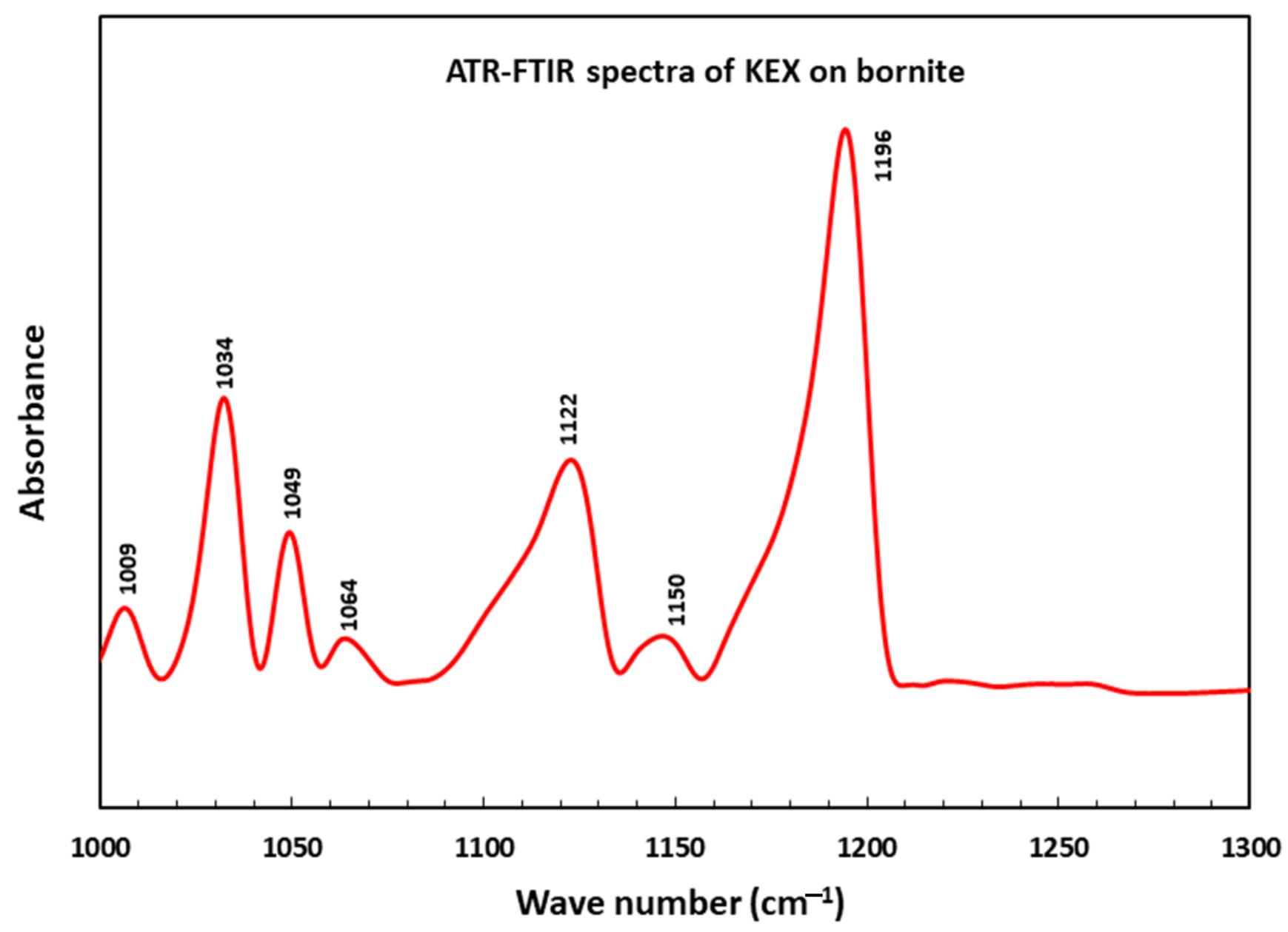

Figure 17. ATR-FTIR spectra of a bornite surface after it contacted the $5 \times 10^{-4} \mathrm{M} \mathrm{KEX}$ solution at pH 6 for $1 \mathrm{~h}$. 


\section{Discussion}

\subsection{Adsorption of Xanthate on Bornite Surface}

As shown in Figures 3-13, a significant amount of adsorbate can be observed on the bornite surface when it contacted xanthate solutions for a specific time. The roughness analysis of the AFM images of a bornite surface in xanthate solutions is summarized and listed as Table 1. In general, during the same timeframe, i.e., $10 \mathrm{~min}$, surface roughness increased when the concentration of xanthate increased. For example, at $\mathrm{pH} 6$, when the concentration of KEX increased from $5 \times 10^{-5} \mathrm{M}$ to $1 \times 10^{-4} \mathrm{M}$, the roughness Ra value increased from $1.919 \mathrm{~nm}$ to $2.372 \mathrm{~nm}$, and the value increased to $2.412 \mathrm{~nm}$ when the concentration was further increased to $5 \times 10^{-4} \mathrm{M}$. A similar trend was also observed for the case of PAX, although the change in values was not as significant as the one as obtained with KEX. The change of the morphology of the bornite surface cannot be attributed to the reaction of the mineral surface with water, because the AFM images obtained with the addition of xanthate solutions are completely different from those shown in Figure 2, which were captured within same timeframe. Therefore, the adsorbate shown in Figures 3-13 must be due to the adsorption of xanthate at the bornite/liquid interface.

Table 1. Roughness analysis of the AFM images of a bornite surface in xanthate solutions.

\begin{tabular}{|c|c|c|c|c|c|}
\hline Xanthate & $\mathrm{pH}$ & Concentration (M) & Image Source & $\operatorname{Ra}(\mathrm{Sa})(\mathrm{nm}) *$ & $\operatorname{Rms}(\mathrm{Sq})(\mathrm{nm}) * *$ \\
\hline KEX & 6 & $5 \times 10^{-5} \mathrm{M}$ & Figure 3 & 1.919 & 2.596 \\
\hline KEX & 6 & $1 \times 10^{-4} \mathrm{M}$ & Figure 4 & 2.372 & 3.072 \\
\hline KEX & 6 & $1 \times 10^{-4} \mathrm{M}$ & Figure 5 & 2.412 & 3.225 \\
\hline KEX & 6 & $5 \times 10^{-4} \mathrm{M}$ & Figure 6 & 4.529 & 5.866 \\
\hline PAX & 6 & $1 \times 10^{-5} \mathrm{M}$ & Figure 8 & 0.665 & 0.861 \\
\hline PAX & 6 & $5 \times 10^{-5} \mathrm{M}$ & Figure 9 & 0.684 & 0.897 \\
\hline PAX & 6 & $1 \times 10^{-4} \mathrm{M}$ & Figure 10 & 0.777 & 1.016 \\
\hline KEX & 10 & $5 \times 10^{-4} \mathrm{M}$ & Figure 12A & 2.664 & 3.907 \\
\hline KEX & 10 & $5 \times 10^{-4} \mathrm{M}$ & Figure 12B & 3.166 & 4.441 \\
\hline KEX & 10 & $5 \times 10^{-4} \mathrm{M}$ & Figure $12 \mathrm{C}$ & 3.464 & 4.734 \\
\hline PAX & 10 & $1 \times 10^{-4} \mathrm{M}$ & Figure 13A & 2.737 & 3.570 \\
\hline PAX & 10 & $1 \times 10^{-4} \mathrm{M}$ & Figure 13B & 2.846 & 3.723 \\
\hline PAX & 10 & $1 \times 10^{-4} \mathrm{M}$ & Figure 13C & 2.792 & 3.655 \\
\hline
\end{tabular}

Note: ${ }^{*} \mathrm{Ra}(\mathrm{Sa})$ : arithmetic average of the absolute values of the surface height deviations. ${ }^{* *} \mathrm{Rms}(\mathrm{Sq})$ : root mean square average of height deviations taken from the mean image data plane.

The adsorption of metal xanthate with a low solubility and the oxidation of xanthate into dixanthogen on a sulfide mineral surface in an aqueous solution, as summarized by Leja [5] and Woods [6], are generally considered the main mechanisms for the increase in hydrophobicity of sulfide minerals in flotation. Previous AFM studies with chalcopyrite and pyrite [17-19] have shown that the adsorbed dixanthogen on sulfides in an aqueous solution demonstrates patches with smooth and round edges, which fits well with the fact that oily dixanthogen is generally insoluble in water and that the circular boundary is the direct result of the high interfacial tension between hydrophobic dixanthogen and water. In addition, under ambient conditions, i.e., room temperature and normal pressure, dialkyl dixanthogen is usually in a liquid form with a low melting point. [25] During an AFM scanning process, a minimal force must be applied because of the softness of dixanthogen [17-19]. In this investigation, as shown in Figures 3-13, the adsorbate had no smooth and round edges, and the morphology was completely different compared to that observed for dixanthogen, which is shown in Figure 14. In addition, the adsorbate on the bornite surface was not 'soft,' and its morphology was not disturbed, even under 
an elevated scan force. For example, as shown in Figures 7-11, a large scan force must be applied to remove the adsorbate and open a 'window' in the center of the AFM image. In addition, Figures 15 and 16 show that the adsorbate on the bornite in the xanthate solution was rigid, with sharp "jump-in" and "jump-off" points on the force curves. Therefore, we ruled out the possibility that observed adsorbate on the bornite was dixanthogen.

This finding, as obtained from the AFM imaging analysis results, is in line with what has been previously reported. For example, Allison et al. [3] reported that xanthate adsorbed on bornite in the form of metal xanthate with low solubility, i.e., $\mathrm{CuX}$. It has been suggested that the final adsorption products on sulfides are highly associated with the semiconductor type of sulfide minerals. That is, dixanthogen is usually formed on n-type minerals, while metal xanthate is observed on p-type minerals. Bornite is classified as a p-type mineral [26], which favors the formation of metal xanthate.

According to Buckley et al. [9], the adsorption of xanthate on bornite is an electrochemical process depending on the potential. When the potential is above $-0.35 \mathrm{v}$, bornite is oxidized in water and yields an iron-free copper sulfide, the reaction of which is shown as follows:

$$
\mathrm{Cu}_{5} \mathrm{FeS}_{4}+3 \mathrm{H}_{2} \mathrm{O}=\mathrm{C} u_{5} \mathrm{~S}_{4}+\mathrm{Fe}(\mathrm{OH})_{3}+3 \mathrm{H}^{+}+3 e
$$

Comparing Figures 1 and 2, the bornite surface that contacted the water was rougher than the surface that contacted air. In the present investigation, the solution potential was not controlled, and the potential value of DI water was higher than $-0.35 \mathrm{~V}$. These results suggest that the bornite surface will undertake oxidation reaction to some extent when it contacts water following the reaction, as shown by Equation (1).

Zachwieja et al. [10] also proposed that the adsorption of xanthate on bornite is due to the following simplified anodic reaction simplified, introducing insoluble cuprous xanthate on the bornite surface:

$$
C u_{5} S_{4}+n X^{-}=n C u X+C u_{5-n} S_{4}+n e^{-}
$$

That is, xanthate adsorbs on bornite mainly in the form of insoluble cuprous xanthate at a low solution potential. The production of dixanthogen on bornite occurs only when the potential is above the rest potential of $X / X_{2}$ couple. In the present study, the solution potential was not controlled, and the value was generally below $-0.1 \mathrm{~V}$. In addition, as mentioned before, no noticeable dixanthogen was observed from the obtained AFM images. Therefore, the adsorbate, as shown in Figures 3-11, is mainly cuprous alkyl xanthate with a low solubility.

In addition, the ATR-FTIR results of the adsorption of KEX on bornite show that the main peaks on the obtained spectra were at $1195 \mathrm{~cm}^{-1}(\mathrm{C}-\mathrm{O}-\mathrm{C}), 1126 \mathrm{~cm}^{-1}(\mathrm{C}-\mathrm{O}-\mathrm{C})$, $1049 \mathrm{~cm}^{-1}$ (S-C-S) and $1032 \mathrm{~cm}^{-1}$ (S-C-S) (Figure 16). The results are almost identical to those that have been reported for the FTIR spectra of $\mathrm{CuX}$ by Poling [23] and Leppinen et al. [24]. In addition, the fact that the characteristic peaks of ethyl xanthate dixanthogen $\left(X_{2}\right)$, namely those at $1020 \mathrm{~cm}^{-1}$ and $1260 \mathrm{~cm}^{-1}$, were not observed on the spectra as obtained rules out the existence of $X_{2}$ on the bornite surface. Therefore, the irregular adsorbate, as shown in Figures 3-11, is basically insoluble cuprous xanthate (CuX). In this sense, the adsorption behavior of xanthate on the bornite is very similar to the adsorption behavior applicable for the case of chalcocite/xanthate systems [20].

\subsection{Effect of the Hydrocarbon Chain of Xanthate}

In froth flotation, the rank and concentration of a collector are two important parameters in determining the collectivity and selectivity of the collector. In general, a xanthate collector with a high rank has a high collectivity and, therefore, a low selectivity, and vice versa. In the present work, the effect of the collector's rank on the adsorption of xanthate on bornite was studied using both KEX and PAX as collectors. Figures 3-11 show that, when the collector's concentration is constant, PAX adsorbs on the bornite surface with a significantly higher surface coverage and a more uniform layer structure. This can be attributed to the fact that the formation of cuprous amyl xanthate occurs at a lower surfactant 
concentration than that for cuprous ethyl xanthate because of the lower-solubility product of cuprous amyl xanthate. For example, it has been reported that the solubility product of cuprous amyl xanthate and cuprous ethyl xanthate is $8.0 \times 10^{-22}$ and $5.2 \times 10^{-20}$, respectively. [27,28] Allison et al. [3] also reported that the percentage of reacted xanthate increased by one-fold, with the carbon number of xanthate increasing from 2 to 5 at the same surfactant concentration. Therefore, the fact that cuprous amyl xanthate forms a more uniform layer than cuprous ethyl xanthate is due to the longer hydrocarbon chain of the former and, therefore, an increased lateral hydrophobic attraction between hydrocarbon chains. Therefore, the higher-rank xanthate, i.e., PAX, is more powerful than the lower rank-xanthate, i.e., KEX, for adsorption on the bornite surface. Therefore, the higher-rank xanthate provides a highly improved flotation collectivity.

Allison et al. [3] observed that "no product of reaction with the methyl and ethyl homologues could be detected, although both reacted very extensively with the surface." They further explained this by stating that "the reaction products are not detected because the lower homologues of cuprous xanthate are extremely insoluble in $\mathrm{CS}_{2}$ and most other solvents and consequently are not extracted from the surface." As shown in Figures 3-7 obtained with the present work, the KEX did adsorb on the bornite intensively, with the mineral surface being fully covered. The binding of the adsorbate, i.e., cuprous ethyl xanthate, and bornite is very strong, and the adsorbate was not removed even after applying a large scan force. In addition, Figure 5 shows that the adsorbate was not extracted from the bornite surface by rinsing with ethanol alcohol.

\subsection{Effect of the Concentration of Xanthate}

According to Equation (2), increasing the concentration of xanthate, i.e., the reactant, makes the reaction moves in the normal direction, resulting in more reaction product, i.e., $\mathrm{CuX}$, produced on mineral surface. This concentration effect of xanthate is clearly shown in the AFM images obtained with the present work. For example, Figures 3, 4 and 6 clearly show that the amount of adsorbate increases greatly in surface coverage and the height of the adsorbate, when the concentration of KEX increases from $5 \times 10^{-5} \mathrm{M}$ to $5 \times 10^{-4} \mathrm{M}$. The same conclusion can also be drawn for the case of PAX. By comparing Figures 8-10, one can see that when the concentration of PAX increases from $1 \times 10^{-5} \mathrm{M}$ to $1 \times 10^{-4} \mathrm{M}$, the amount of adsorbate increases at a same contacting time.

\subsection{Effect of Adsorption Time}

Figures 6, 7, 10 and 11 show that the height of the adsorbate and the surface coverage increased when the adsorption time increased from $10 \mathrm{~min}$ to $20 \mathrm{~min}$ in the xanthate solution at $\mathrm{pH}$ 6. In addition, as shown in Figure 12A-C and Figure 13A-C, the adsorption increased when the adsorption time increased from $5 \mathrm{~min}$ to $10 \mathrm{~min}$ and further to $20 \mathrm{~min}$ in the xanthate solution at $\mathrm{pH} 10$. The trend was much more evident in the case of KEX. All these images clearly show that the adsorption of the xanthate on bornite increased with the adsorption time. The finding is in line with a common industrial practice of copper ore beneficiation, which involves adding collectors in a mill to increase the adsorption time, as well as the benefit from the adsorption of the collector on the freshly exposed mineral surface.

\subsection{Impact of Xanthate on Bornite Flotation}

In froth flotation, specific chemicals, i.e., collectors or promoters, are added to the pulp to increase the surface hydrophobicity of a target mineral. This results in the increase of both the attractive hydrophobic force and the adhesion force between the mineral particles and bubbles. The former can facilitate a particle/bubble attachment, and the latter can retard a particle/bubble detachment, which are both beneficial for froth flotation.

According to Cassie's equation [29]:

$$
\cos \theta=f_{1} \cos \theta_{1}+f_{2} \cos \theta_{2}
$$


where $\theta_{1}$ is the contact angle for component 1 with a surface area fraction $f_{1}, \theta_{2}$ is the contact angle for component 2 with surface area fraction $f_{2}$ and $\theta$ is the contact angle of the composite material. In addition, $f_{1}+f_{2}=1$ for the case of the adsorption of the collector on the bornite surface, assuming that component 1 is the bare bornite and component 2 is the adsorbate, i.e., $\mathrm{CuX}, \theta_{2}$ should be larger than $\theta_{1}$. Therefore, increasing $f_{2}$ and /or $\theta_{2}$ will increase $\theta$, i.e., the hydrophobicity of bornite with adsorbate, resulting in a better flotation.

In the present study, as shown in the AFM images, it is clear that xanthate can effectively adsorb on a bornite surface, as xanthate showed an almost full coverage at a concentration above $1 \times 10^{-5} \mathrm{M}$ PAX. This suggests that the adsorption of cuprous xanthate resulted in a large $f_{2}$, which is beneficial for a large $\theta$. Increasing the dosage of xanthate and adsorption time will increase the cuprous xanthate's surface coverage, i.e., $f_{2}$, and it is also beneficial for to increase the surface hydrophobicity.

The force measurement results show that the detach forces measured in the xanthate solutions were larger than the force measured with water. In general, a large detach force suggests a large adhesion between a probe and substrate through the media. Following the Derjaguin approximation [30], it is predicted that a larger adhesion force will be achieved when the probe/liquid/bornite interfacial tension increases. In the present investigation, the $\mathrm{Si}_{3} \mathrm{~N}_{4} \mathrm{AFM}$ probe was inert in water, and it did not directly react with xanthate. Therefore, the surface energy of the $\mathrm{Si}_{3} \mathrm{~N}_{4}$ probe did not change. In addition, in the present study, the surface tension of water media remained the same because the short-chain xanthate surfactant was used at a very low concentration. Therefore, the increase in the detachment force, as shown by the AFM force measurement, was mainly due to the increase of the interfacial tension between bornite and water, suggesting an increase in the hydrophobicity of bornite because of the adsorption of the cuprous xanthate on the mineral surface. We also suggest carrying out an AFM "colloid force" measurement by directly measuring the interaction force between a hydrophobic "colloid probe" and the adsorbate on bornite surface. The results will help to better understand the interaction between a bubble and a bornite particle in xanthate solutions in froth flotation. Such an investigation of force measurement, which is beyond the scope of the present study, is recommended for a future work.

\section{Conclusions}

AFM surface image measurements were applied to study the adsorption of xanthate on bornite in an aqueous solution in situ. The AFM images showed that the xanthate adsorbed on the mineral surface strongly when bornite contacted the KEX and PAX solution. The ATR-FTIR result confirms that that the adsorbate was essentially cuprous xanthate. Increasing the hydrocarbon chain length of xanthate increased the collectivity of the collector by increasing the surface coverage of the cuprous xanthate on the mineral surface at a lower concentration. Both increasing the chemical dosage and increasing the adsorption time will increase the surface coverage of $\mathrm{CuX}$ on mineral surface, which contributes to a better flotation by increasing the surface hydrophobicity of bornite.

Funding: This research received no external funding.

Data Availability Statement: The data presented in this study are available on request from the corresponding author. The data are not publicly available due to ethical.

Acknowledgments: J. Zhang is grateful to Freeport-McMoRan Copper \& Gold, Inc. for sponsoring the Freeport McMoRan Copper and Gold Chair in Mineral Processing in the Department of Mining and Geological Engineering in the University of Arizona. Reviewers' insightful comments and valuable suggestions are greatly appreciated.

Conflicts of Interest: The authors declare no conflict of interest.

\section{References}

1. Gaudin, A.M.; Schuhmann, R., Jr. The action of potassium n-amyl xanthate on chalcocite. J. Phys. Chem. 1936, 40, 257-275. [CrossRef] 
2. Poling, G.W.; Leja, J.J. Infrared study of xanthate adsorption on vacuum deposited films of lead sulfide and metallic copper under conditions of controlled oxidation. Phys. Chem. 1963, 67, 2121-2126. [CrossRef]

3. Allison, S.A.; Goold, L.A.; Nicol, M.J.; Granville, A.D. A determination of the products of reaction between various sulfide minerals and aqueous xanthate solution, and a correlation of the products with electrode rest potentials. Metall. Trans. 1972, 3, 2613-2618. [CrossRef]

4. Fuerstenau, M.C. Sulphide mineral flotation. In Principles of Flotation; King, R.P., Ed.; South African Institute of Mining and Metallurgy Monograph Series: Johannesburg, South Africa, 1982; pp. 159-182.

5. Leja, J. Surface Chemistry of Flotation; Plenum Press: New York, NY, USA, 1982.

6. Woods, R. Electrochemistry of sulphide flotation. In Principles of Mineral Flotation, The Wark Symposium; Jones, M.H., Woodcock, J.T., Eds.; AIMM: Melbourne, Victoria, Australia, 1984; pp. 91-115.

7. Mielczarski, J.; Suoninen, E. XPS study of ethyl xanthate adsorbed onto cuprous sulphide. Surf. Interface Anal. 1984, 6, 34-39. [CrossRef]

8. Mielczarski, J. XPS study of ethyl xanthate adsorption on oxidized surface of cuprous sulfide. J. Colloid Interface Sci. 1987, 120, 201-209. [CrossRef]

9. Buckley, A.N.; Hamilton, I.C.; Woods, R. Lnvestigation of the Surface Oxidation of Bornite by Linear Potential Sweep Voltammetry and X-ray Photoelectron Spectroscopy. J. Appl. Electrochem. 1984, 14, 63-74. [CrossRef]

10. Zachwieja, J.B.; Walker, G.W.; Richardson, P.E. Electrochemical flotation of sulfides: The bornite-ethylxanthate system. Miner. Metall. Process. 1987, 4, 146-151. [CrossRef]

11. Hangone, G.; Bradshaw, D.; Ekmekci, Z. Flotation of a copper sulphide ore from Okiep using thiol collectors and their mixtures. J. SAIMM 2005, 105, 199-206.

12. Dhar, P.; Thornhill, M.; Rao Kota, H. Investigation of Copper Recovery from a New Copper Ore Deposit (Nussir) in Northern Norway: Dithiophosphates and Xanthate-Dithiophosphate Blend as Collectors. Minerals 2019, 9, 146. [CrossRef]

13. Polkin, S.I.; Kuzkin, S.F.; Golov, V.M. Application of radiography to studies on the mechanism of interaction between flotation reagents and mineral surfaces. Non-Ferr. Metal: Moscow, Russia, 1955.

14. Plaksin, I.N.; Shafeyev, R.S.; Zaiteseva, S.P. Applications of autoradiography to studies of flotation reagents disposition on mineral surfaces. Proc. Acad. Sci. S.S.S.R. 1956, 108.

15. Kim, B.S.; Hayes, R.A.; Prestidge, C.A.; Ralston, J.; Smart, R.S.C. In-situ scanning tunneling microscopy studies of galena surfaces under flotation-related conditions. Colloids Surf. A 1996, 117, 117-129. [CrossRef]

16. Smart, R.S.C.; Amarantidis, J.; Skinner, W.; Prestidge, C.A.; Vanier, L.L.; Grano, S.R. Surface analytical studies of oxidation and collector adsorption in sulfide mineral flotation, in Wandelt, K. and Thurgate, S. (ed), Solid-Liquid Interfaces. Top. Appl. Phys. 2003, 85, 3-62.

17. Zhang, J.; Zhang, W. An AFM study of chalcopyrite surface in aqueous solution. In Proceedings of the SME Annual Meeting preprint, Phoenix, AZ, USA, 21-24 February 2010.

18. Zhang, J.; Zhang, W. The Adsorption of Collectors on Chalcopyrite Surface Studied by an AFM in 'Separation Technologies'; Young, C., Luttrell, G., Eds.; SME: Englewood, CO, USA, 2012; pp. 65-73. ISBN 978-0-87335-339-7.

19. Zhang, J.; Zhang, W. An atomic force microscopy study of the adsorption of collectors on chalcopyrite. In Microscopy: Advances in Scientific Research and Education; Méndez-Vilas, A., Ed.; Formatex Research Center: Badajoz, Spain, 2014; Volume 2, pp. 967-973. ISBN 978-84-942134-4-1.

20. Zhang, J.; Zhang, W. An AFM study of the adsorption of collector on chalcocite. In Proceedings of the SME Annual Meeting Preprint 15-138, Denver, CO, USA, 15-18 February 2015.

21. Zhang, J.; An, D.; Withers, J. A Micro-Scale Investigation of the Adsorption of Collectors on Bastnaesite. Min. Metall. Explor. 2019, $36,957$.

22. An, D.; Zhang, J. A Study of Temperature Effect on the Xanthate's Performance during Chalcopyrite Flotation. Minerals 2020, 10, 426. [CrossRef]

23. Poling, G.W. Infrared Studies of Adsorbed Xanthates. Ph.D. Thesis, University of Alberta, Edmonton, AB, Canada, 1963.

24. Leppinen, J.O.; Basilio, C.I.; Yoon, R.H. In-situ FTIR study of ethyl xanthate adsorption on sulfide minerals under conditions of controlled potential. Int. J. Miner. Process. 1989, 26, 259-274. [CrossRef]

25. Rao, S.R. Xanthate and Related Compounds; Dekker: New York, NY, USA, 1971.

26. Shuey, R.T. Semiconducting Ore Minerals; Elsevier: Amsterdam, The Netherlands, 1975.

27. Kakovsky, I.A. Physiochemical properties of some flotation reagents and their salts with ions of heavy non-ferrous metals. In Proceedings of the Second International Congress of Surface Activity, London, UK, 1 January 1957; pp. $225-237$.

28. Ackerman, P.K.; Harris, G.H.; Klimpel, R.R.; Aplan, F.F. Evaluation of flotation collectors for copper sulfides and pyrite, III. Effect of xanthate chain length and branching. Int. J. Miner. Process. 1987, 21, 141-156. [CrossRef]

29. Cassie, A.; Baxter, S. Wettability of porous surfaces. Trans. Faraday Soc. 1944, 40, 546-551. [CrossRef]

30. Derjaguin, B.V. Friction and adhesion. IV. The theory of adhesion of small particles. Kolloid-Zeitschrift 1934, 69, 155-164. [CrossRef] 